\title{
Encouraging Commitment in Online Communities
}

Yuqing Ren, Robert Kraut, Sara Kiesler \& Paul Resnick

In Kraut, R. E. \& Resnick, P. \%ХIQUQJ6XFFHMXO2 QOQH\&RP P XQUMHМ

( YIAHQHH\%DHGRFLO HMJQ Cambridge, MA: MIT Press.

1. Affective Commitment: Wanting to Stay …........................................................... 3

1.1 Encouraging identity-based commitment ................................................... 4

1.2 Bonds-based commitment............................................................................ 10

1.3. Reducing repelling forces that undercut personal commitment ......................... 18

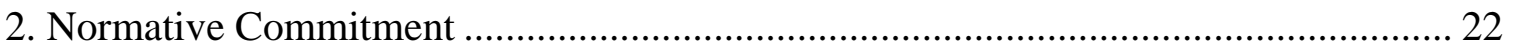

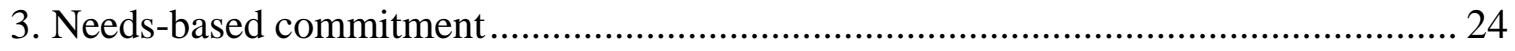

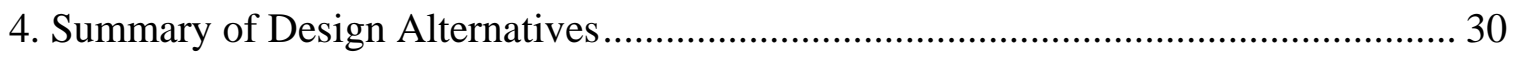


Community designers can draw from theories of commitment to make design decisions that influence whether and how people will become committed to a community. Commitment is harder to achieve than a flow (or trickle) of visitors, but for most online communities, commitment is crucial. Committed members work harder, say more, do more, and stick with a community after it becomes established. They care enough to help with community activities and to sustain the group through problems. Committed members are those most likely to provide the content that others value, such as answers to people's questions in technical and health support groups (Blanchard and Markus 2004; Fisher et al. 2006; Rodgers and Chen 2005), code in open source projects (Mockus et al. 2002), and edits in Wikipedia (Kittur et al. 2007). They are more likely to exercise voice, demanding change and improvement when dissatisfied, than to exit (Hirschman, 1970).

Indeed, commitment is a building block for solving challenges described in the remaining chapters of this book. Commitment to the community makes people care enough to respond to and to enforce norms of appropriate behavior (Smith, McLaughlin, \& Osborne, 1997) and thus commitment is a building block for regulation, as discussed in Chapter TKTK. Commitment to the community makes people motivated to exert effort behind the scenes to keep the online community going (Butler et al. 2007), and thus commitment is a building block for motivating contributions, as discussed in Chapter TKTK. And commitment to a new community leads people to overlook growing pains or outside alternatives during a community startup phase, as discussed in Chapter TKTK.

Social scientists have devoted years of research into discovering the difference between commitment and flight. Commitment to a group, organization or community can be based on their feelings of closeness to other individuals in the group, their feelings of strong identification with the group or its main interest, their feelings of obligation to the community, or even on the costs or risks of leaving the community (Festinger, Schachter, and Back 1950, Johnson 1982, 1991a;Allen and Meyer 1990; Prentice et al. 1994). Our knowledge about why and how people become committed to communities has its roots in a post-World War II theory of groups, called "field theory.” Field theory was invented by Kurt Lewin (“Le-veen”), a psychologist who emigrated to the United States when the Nazis took over Germany. Lewin was fascinated by group dynamics. He wondered what it was that caused people to follow a leader, form cohesive units, and develop loyalty as members of a group. Lewin rejected the idea that people's loyalty to a group is based only in their individual personality or personal history. He observed that, in the right environment, a group could attract very strong group feelings from all sorts of people. Field theory looked to the forces in people's environment (or "field") that attracted them to a group and kept them loyal (Lewin, 1951).

Kurt Lewin and his graduate students, such as Leon Festinger, Bernice Lott, and Roger Barker, invented ingenious laboratory experiments on group dynamics as well as methods for measuring people's behavior in naturally formed groups. They discovered many patterns that occurred over and over again, such as the principle of proximity--the way in which simply living or working near people initiates a sense of identity and group feelings with those nearby. They discovered various ways that a group's autocratic or democratic management changed the group's 
dynamics. Kurt Lewin's passion for empiricism and insights into how people experienced the group environment was a major influence on the science of commitment that exists today.

Hundreds of studies later, theories of group psychology distinguish among three types of commitment that we can apply to online communities: (1) affective commitment, based on feelings of closeness and attachment to a group or members of the group, (2) normative commitment, based on feelings of rightness or felt obligation to the group, and (3) need-based or continuance commitment, based on an incentive structure in the group and alternatives available to members from outside that increase the net costs of leaving the group (Allen \& Meyer, 1996; Meyer \& Allen, 1991; Meyer, Stanley, Herscovitch, \& Topolnytsky, 2002). These forces combine to determine an individual's decision to continue membership in a group. According to this perspective, a committed person has one or more of three subjective experiences in the group: wanting to continue as a member of the group (affective commitment), feeling he or she ought to continue (normative commitment), and feeling that he or she must continue --or at least is better off in the group than out of it (need-based commitment). The rest of this chapter discusses how online community design influences each of these experiences.

\section{Affective Commitment: Wanting to Stay}

Social psychologists who study groups distinguish between two bases for the affective commitment people have towards groups. Identity-based affective commitment is a feeling of being part of the community and helping to fulfill its mission. In contrast, bond-based affective commitment is feeling close to individual members of the group. The person who feels attached to the community as a whole will want to be part of the community and to further its purpose. The person who feels attached to specific people in the group may be more committed to these close individuals than to the group as a whole. Of course people can feel both types of attachment in the same community, but these feelings stem from different causes, so for purposes of design, we need to distinguish between identity-based commitment and bonds-based commitment. Even though both identity-based commitment and bond-based commitment lead people to feel loyalty to their community, stay with it longer and contribute more to, we highlight the distinction between them here because these type types of commitment have some distinct causes and consequences, with implications for how designers can encourage and exploit the two types of commitment (Ren, Kraut, \& Kiesler, 2007)

The distinction between identity-based commitment and bonds-based commitment can be traced to Festinger, Schachter, and Back's (1950) theory of group cohesiveness. They identified two ways that commitment to a group is formed: through the attractiveness of the group or through the attractiveness of individual group members. Commitment because of the attractiveness of the group as a whole became the focus of social identity theory (M. Hogg \& Abrams, 1988). This theory emphasizes how sharing a common social category with others- e.g., gender race, geographic location, nationality, hobby, or political party -- causes people to categorize themselves as a rightful member of a group and to identify with it. Thus a woman in the information technology industry in Pittsburgh might feel connected to online communities associated with the women in computer science (http://systers.org), the Pittsburgh Steelers

3-Ren10-Commitment 0912v10-Ss.Doc last saved 11/30/10 
football team (http://www.steelersfever.com) or the Facebook alumni group for her alma mater. Having members with identity-based commitment has many interesting effects on an online community. For example, when members feel strong identity-based commitment, they may stick with the group even if their friends leave.

More interpersonal-based commitment is the type that forms when members of a community become psychologically close to some others in the community and feel bonds of mutual liking. This form of commitment is based upon idiosyncratic preferences and is firmly dependent on close personal interaction (Lott $\&$ Lott, 1965). Friendship groups are vulnerable to member turnover because friends can leave as a clique (e.g., Krackhardt \& Porter, 1986).

The differences in attitudes of those who feel identity-based commitment versus bonds-based commitment have been demonstrated in empirical studies. Prentice, Miller, \& Lightdale, (1994) classified topic-based university student groups such as art groups, school newspapers, and sports teams, as common identity groups. These are groups to which students belong more because of the activities they do than because of individual friendship. The researchers differentiated these groups from largely friendship or bond-based groups such as fraternities and eating clubs. Members of the common identity groups reported feeling more attached to their group as a whole than to their fellow group members, whereas members of the common bond groups reported feeling attached both to the group as a whole and to group members. The authors argued that "the two perspectives might ... be viewed as describing two separable processes in the development and maintenance of groups, either of which might dominate under a given set of circumstances" (Prentice, Miller \& Lightdale, 1994: 490).

The distinction between identity-based and bond-based attachment also has been made in studies of online communities (e.g., Postmes \& Spears, 2000; Sassenberg, \& Postmes, 2002; Utz, 2003; Utz, \& Sassenberg, 2002). In general, common identity in the online context implies that members feel a commitment to the online community's purpose or topic. The following message sent by an existing member of a cancer support group to a newcomer illustrates this identitybased attachment. "Welcome to the list nobody wants to join. While it really stinks to have to be here, you'll find a wealth of experience. You'll find many excellent suggestions and tips prior to surgery in the archives." Common bond in the online context, in contrast, implies that members feel socially or emotionally attached to particular members of the online community. The following quote from a thank you note from one member of the cancer-support group to another illustrates the closeness of the bond developed between the two. "Thanks for your kind words YOU [sic] are an inspiration to me ... ! I still remember that you were the first to respond to my first post on this list, more than $4+$ years ago.”

\subsection{Encouraging identity-based commitment}

Social identity theory states that identification with a social group or category is a very powerful force that can keep people in a group. Identity-based commitment occurs when people feel connected to the group as a whole or its purposes, incorporating aspects of the group into their personal sense of identity or the way they think about themselves. For instance, people can 
become strongly committed to the Sierra Club, the National Rifle Association, a movie discussion group, a software development project or a blog community without knowing others in these organizations.

When people identify with a community or group as a whole, they tend to perceive other members in the group as interchangeable (Turner, 1985). One consequence is that their commitment to the group is stable in the face of turnover in membership, at least in comparison to bond-based attachment (Abrams, Ando, \& Hinkle, 1998).

Design claim 1. Instilling identity-based attachment leads people to continue their participation in the group in the face of membership turnover.

Postmes and his colleagues(2002) compared the influence of group norms in common-identity versus common-bond online groups. They found that attitudes were more similar in commonidentity groups than in common-bond groups. Sassenberg (2002) found similar results using a behavioral measure of compliance to group norms. Thus research so far indicates that online community members who feel identity-based attachment to the community will be more likely to conform with group norms than those who feel bond-based attachment to the community. As discussed in the chapter TKTK, group norms are especially valuable in regulating misbehavior.

Design claim 2: Identity-based commitment makes people more compliant with norms than does bond-based commitment.

Similarity can create identity-based attachment. (It can also lead to bonds-based attachment, as will be described in the next section.) Similar member background such as profession, school, locality, race, ethnicity, occupation, and age, especially when these attributes are shared among people who are otherwise strangers, may lead to common category membership. Further, people tend to dislike groups whose members are heterogeneous, and these groups experience high turnover, especially when conflict arises (Williams, 1998). Similarity of background or expertise leads to common identity most when the similarity is relevant to the group's context and functioning (Cartwright, 1968). Recruiting similar people into a community or clustering existing members so that similar people can form subgroups will increase identity-based commitment to a community. ACOR, the Association of Cancer Online Resources ${ }^{1}$, a support community for patients with cancer and their caregivers, offers support through over 150 distinct mailing lists for people suffering with different types of cancer. In contrast, the support groups at the Cancer Support Community are heterogenous in terms of diagnosis. ${ }^{2}$ The research literature indicates that because of its specificity the ACOR approach will be more successful in developing identity-based commitment. Communities can let individuals select into

\footnotetext{
${ }^{1}$ http://www.acor.org/

${ }^{2}$ http://online.cancersupportcommunity.org
} 
homogeneous subgroups, as ACOR does, or can use statistic techniques to assign people with similar attributes together. For example, Harper and his colleagues developed efficient algorithms to subdivide a larger community into approximately equally-sized clusters of participants who are similar to each other (Harper, Sen, \& Frankowski, 2007).

Design Claim 3. Recruiting or clustering those who are similar to each other into homogeneous groups will foster identity-based commitment to a community.

Community designers can encourage people to identify with an online community or with subgroups within it by highlighting members' common social characteristics and by drawing boundaries around this category. In traditional groups, people categorize themselves on criteria such as gender, hometown, religion, job, academic major, leisure interests, organizational membership, or political values that they deeply care about. However, a social category does not have to be meaningful in the larger population or even important to the individual to induce identification with a group. Tajfel (1971)demonstrated that randomly labeling a group with an arbitrary label ("over-estimators" or "under-estimators") could activate common identity in research groups, even if people did not know others in their group. This phenomenon has been replicated many times in laboratory experiments and online. One can induce social identity by , categorizing people with fictions personality traits (Amichai-Hamburger, 2005), team uniforms (Dabbish \& Kraut, 2008; Worchel, Rothgerber, Day, Hart, \& Butemeyer, 1998) or arbitrary group names (Michinov, Michinov, \& Toczek-Capelle, 2004; Ren, et al., Under review),

Design claim 4: Providing a collection of individuals with a name or other indicator that they are members of a common group will increase their identity-based commitment to the community.

In most online communities, people have come to the group based on their shared interests in a particular domain (e.g., Perl programming), topic (e.g., autism, greyhound rescue, the Steelers), or common cause (e.g., building a free online encyclopedia). People are attracted to the community to the extent that they identify with the domain, topics or causes on which the community is based and find them meaningful. They value their membership because affiliation with the community enables them to affiliate with the topic or cause, access and share useful information, or contribute toward a meaningful cause.

In the community startup chapter, we argued for the importance of a clearly articulated scope, with a clever name and tagline, because it helps to define a community's niche and differentiate it from competitors. In the newcomers' chapter, we argued that a clearly articulated scope helps potential new members assess whether they fit well. Here, we point out a third benefit of a clear scope, especially one that is articulated through a distinctive name: it induces identity-based attachment. Good examples are Wikipedia, "the free encyclopedia that anyone can edit," dogster.com "for the love of dog," or hattrick.org, whose motto "Everybody deserves their own football team” reflects its mission as a fantasy football (soccer) game.

Design claim 5: A name and tagline that articulate the shared interests of a community's members will increase the members' identity-based commitment to the community. 
However, as the community grows, members may start to cluster into natural subgroups. Subgroup identity can be as powerful as whole-community identity in eliciting commitment in its own right and can enhance commitment to the whole community (Zaccaro \& Dobbins, 1989). To further this process, designers can actively promote or create subgroups. Kittur and Kraut (2008) found that when Wikipedia editors joined a named project within the larger encyclopedia, they increased their overall editing in the encyclopedia and directed more of their editing to work that was within the scope of the project they joined. In an experiment in an online setting, Beenen et al (2004) increased contributions to an online movie site by telling people that they were members of the fictitious "Explorers' group" and then assigning the Explorers a group goal. In actuality, the Explorers were a group in name only: "members" never found out who the other members were or communicated with them. Yet people assigned to the Explorers and given a group goal logged in $10 \%$ more and contributed $65 \%$ more movie ratings than those who were given a commensurate individual goal but not assigned to a group.

Design claim 6: Creating named groups within a larger online community will increase members' commitment to the subgroups.

In most cases, identity-based attachment to subgroups complements rather than supplants commitment to the community as a whole. Ren et al (Under review) created subgroups among people with similar movie tastes within a movie community, giving them arbitrary names like the Eagles or Gorillas. Creating these subgroups increased members' self-reported commitment to the overall community and increased their frequency of visiting the site over a six month period by $44 \%$, compared to other participants who were not assigned to subgroups.

Sometimes, however, the subgroup identity can be stronger than the group identity, and when there is a conflict between the two, the subgroup identity may prevail. For example, Amy Jo Kim chronicles the "Group That Got Away," a guild in the role-playing game Meridian 59 that left as a group to play another game (2000, p. 319).

Design claim 7: Creating named groups within a larger online community will increase members' commitment to the community as a whole, as long as the subgroup identity is not in conflict with the larger community identity.

A common fate, goal, purpose task can enhance identity-based commitment (Sherif, Harvey, White, Hood, \& Sherif, 1961). Common fate is the perception that all community members either benefit from the same reward or suffer from the same costs (Michinov, et al., 2004; Worchel, et al., 1998). For example, if a community is in danger of closing because its servers cost too much to run or is in danger of being overwhelmed by spam messages, everyone will be affected. A common goal in a community is a goal that the group as a whole can attain, such as a high score, ratings, or some tangible outcome. When a guild in a multi-player game goes on a quest, the players will either all succeed or all fail together. Guilds in online game environments often identify their group goals in their profiles. The guild Lords of Eternity declares, "Our goal is to defeat current raid content and work towards the heroic hard modes and meta-achievements 
as efficiently as quickly as possible. We strive for 5-night progress on a 3-night schedule ${ }^{3}$.” Like many guilds, Lords of Eternity tallies its achievements and progress towards its goals on the guild websites. Another example of common goals can be seen in political subgroups on Facebook, whose members share the mission of getting their candidate elected. During the 2008 presidential campaign, the John McCain Facebook Challenge group expressed a mission was to "Get every Republican on Facebook to go to John McCain's Facebook page ... and become a supporter" and the largest Facebook group for Barack Obama put a goal right into its title: "One Million Strong for Barack".

Advocacy communities and production-oriented communities such as open-source software or open content repositories often articulate a common purpose that generates identity-based commitment, even when the purpose is not translated into quantifiable goals against which progress can be tracked. Bryant, Forte and Bruckman (2005) describe how the common goal of developing the world's best encyclopedia led readers of Wikipedia to become "Wikipedians," active contributors committed to the community. As three Wikipedia participants remarked:

"I really got inspired by the idea [of the Wikipedia]. I'd say a lot of what hooked me was the community aspect and knowing that I was contributing something that was going to be around for a while..."

"I believe in the integrity of the project. I want to see it succeed, especially the articles people will look up..."

"It has a dedicated task and it's producing a product... at least with the Wikipedia [versus Usenet and the like] you can convince yourself you're doing something to benefit mankind. .."

Design Claim 8. Making community fate, goals, or purpose explicit will increase members' identity-based commitment to the community.

A joint task is a one that involves inputs from all members. Groups whose members are cooperatively interdependent because they have a joint task tend to be more cohesive and committed to the group (Gaertner, et al., 2000; Worchel, et al., 1998). Indeed, assigning people a difficult to achieve, interdependent task is a powerful way to overcome even strongly felt animosity among subgroups within a community (Sherif, et al., 1961) Interdependence through a joint task not only fosters identification with the community as a whole but also normative commitment. Members come to feel that the group depends on them and will actually use and benefit from their work. Many online communities try to foster the perception of task interdependence. Guilds in massively multiplayer games that take on difficult to achieve tasks, like receiving good loot from killing powerful monsters, are creating identity-based commitment. So do to WikiProjects when they attempt to improve one of their articles to featured class, so it appears on the Wikipedia home page. xxx

\footnotetext{
${ }^{3}$ http://www.wowprogress.com/guild/us/garona/Lords+of+Eternity
} 
Design Claim 9. Providing community members interdependent tasks will increase their identity-based commitment to the community and reduce conflict among subgroups.

In-groups imply out-groups. By definition, being in a group means that there are one or more contrasting groups one is not in. People who define and categorize themselves as members of a group often compare themselves with those in other groups (M. A. Hogg \& Terry, 2000). Making these contrasts explicit can intensify people's identification and commitment. In experiments, researchers have divided participants into two or more groups to highlight group boundaries. Doing so intensified participants' identification with their own group (T. Postmes, Spears, Sakhel, \& de Groot, 2001; Rogers \& Lea, 2005; Worchel, et al., 1998). The out-group did not have to be physically or even virtually present to elicit intergroup comparisons and ingroup commitment(Utz, 2003; Yuki, Maddux, Brewer, \& Takemura, 2005).

In online communities, designers can encourage members to attend to group boundaries and their identification with the group by increasing members' awareness of a different "outgroup.” Blizzard, the developer and operator of World of Warcraft, built comparisons at the core of their game by requiring that each player choose between being a member of one or the other of the opposing factions, The Alliance or The Horde (see Figure 1). Also, guild-level rankings in World of Warcraft and other group-oriented online games build increased identification by highlighting the presence and threat of an out-group. More informally, posters on the Frequently Asked Questions (FAQ) page on apache.org compare the speed, performance and market-share of the

\section{HORDE VS. AlliahCE F.A.Q.}

Who are the Horde and Alliance? The Horde and Alliance are the two sides battling for control of the world. In years past, they fought brutal wars against each other, but today, they have settled into a tenuous stalemate. ... Still, the Horde and Alliance are hostile to each other, and members of one faction are never welcome in the cities of the other.

(http://www.worldofwarcraft.com/info/faq/horde valliance.html)

Figure 1. What are the Horde and Alliance in World of Warcraft Apache server with those of other commercial servers, fostering the common identity of those who work on Apache software. The Wikipedia project site uses a similar technique by highlighting competition with other encyclopedias. The authors of the entry on Wikipedia itself noted that Jimmy Wales, the founder of the project, "intends for Wikipedia ultimately to achieve a 'Britannica or better' level of quality and be published in print” (Anonymous, 2006).

Design Claim 10. Highlighting an out-group (and competing with it) will increase members' identity-based commitment.

The power of an out-group to intensify group commitment is enhanced when people already feel connected to the group and perceive their group to be threatened (Hutchison, Jetten, Christian, \& Haycraft, 2006). The surge of American patriotism after terrorist attacks on the World Trade Center and Pentagon illustrate this point. Some citizens reacted with anger, and some with sadness, but both groups increased their commitment to the United States. Research suggests that 
failure or threat is especially likely to strengthen commitment to a community when they come from external sources or can be overcome with collective effort from group members (Lott \& Lott, 1965). This is why many political leaders prefer to blame other countries for problems in their own.

Community designers must be careful when highlighting a threat to a group, because the effects of threat can backfire. In general, research shows that people prefer to stay with a group that is successful or has high status(Hinds, Carley, Krackhardt, \& Wholey, 2000). Moreover, core and peripheral members may respond to failure and threats differently - core members to strengthen their attachment to justify the additional effort they exert to overcome the difficulty whereas peripheral members are more likely to leave the group when it is an option (L Festinger, Riecken, Schachter, \& Aronson, 1956). When leaving is not an option, in the face of threat both core and peripheral members, will identify more strongly with the group (add reference from community psychology).

Design Claim 11. Emphasizing a threat to the group, especially from an external source, will increase the identity-based commitment among core members, but may undermine the commitment of more peripheral members

Generally, anonymity of individual group members fosters community identity and strong group norms because it de-emphasizes individual distinctions. By contrast, making personal identity salient or individual members identifiable decreases identity-based attachment (though it may increase bond-based attachment) (Tom Postmes, Spears, Lee, \& Novak, 2005; T. Postmes, et al., 2001; K. Sassenberg, 2002; Kai Sassenberg, Boos, Postmes, \& Reips, 2003; Kai Sassenberg \& Postmes, 2002).

\section{Design Claim 12. Making group members anonymous will foster identity-based commitment}

\subsection{Bonds-based commitment}

People may become committed to a group by developing connections to the people who comprise the group. In this case, their commitment is not necessarily to the group as a whole but rather to the other members they know and like. Gross and Martin (1952, pp. 553-554), in their discussion of bonds-based commitment, talked about group cohesiveness as "the resistance of a group to disruptive forces" and proposed that such cohesiveness is associated with the strength of the relational bonds among group members. (see also Lott \& Lott, 1965)

In order to build bonds-based commitment, online community designers can either try to recruit members who are already friends, or build new friendships. Backstrom and his colleagues (2006) showed that the likelihood that a person would join a group in the social networking and blogging site livejournal.com increased with the number of the people they were linked to who were already members of that group (see Figure 2Error! Reference source not found.). Leskovic and his colleagues (2010) showed empirical support for this prediction in both epionions.com and Wikipedia. People who like the same things tend to form direct links between each other, although balance theory is not the only explanation for this result (Leskovec, 
Huttenlocher, \& Kleinberg, 2010). Many online communities do recruit among friends, for example, by mining current members' email lists. Facebook suggests "friending" people with common network ties. Doing so not only increases the likelihood that a newcomer will join a community, because it is frequented by friends, but also increases the mutual bonds among community members.

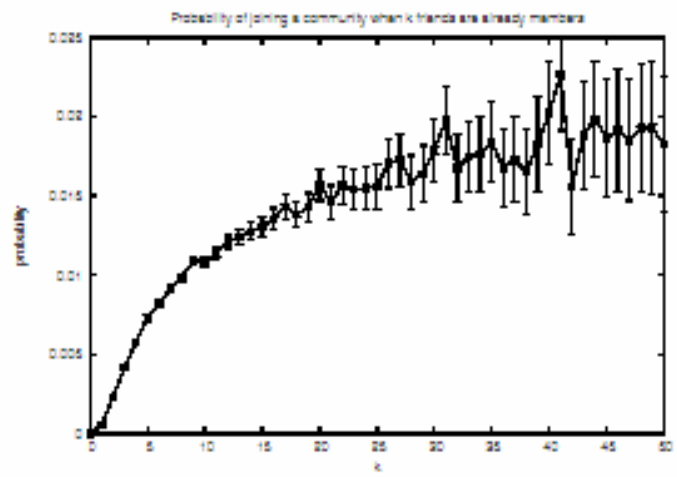

Design Claim 13. Recruiting participants who have existing social ties to be members of the community will increase their bondsFigure 2. The probability p of joining a LiveJournal community as a function of the number of friends $k$ already in the community (From Backstrom et al 2006). based commitment to the community.

The next best thing to building a site with people who have existing friendships may to encourage friends of friends to join. Research on psychological balance demonstrates that people who are both friends of friends are likely to know and like each other and their friendship to a common partner is likely to lead to their becoming friends as well (Curry \& Emerson, 1970; Heider, 1958) Yuki et al. (2005)found that people were more trusting of those who knew they had a shared acquaintance among their in-group members. A friend's friend was a friend online. That is the principle behind social network sites. For example, LinkedIn provides tools for people see friends of friends (see Figure 3), while FaceBook encourages peoples to connect with friends' friends. 


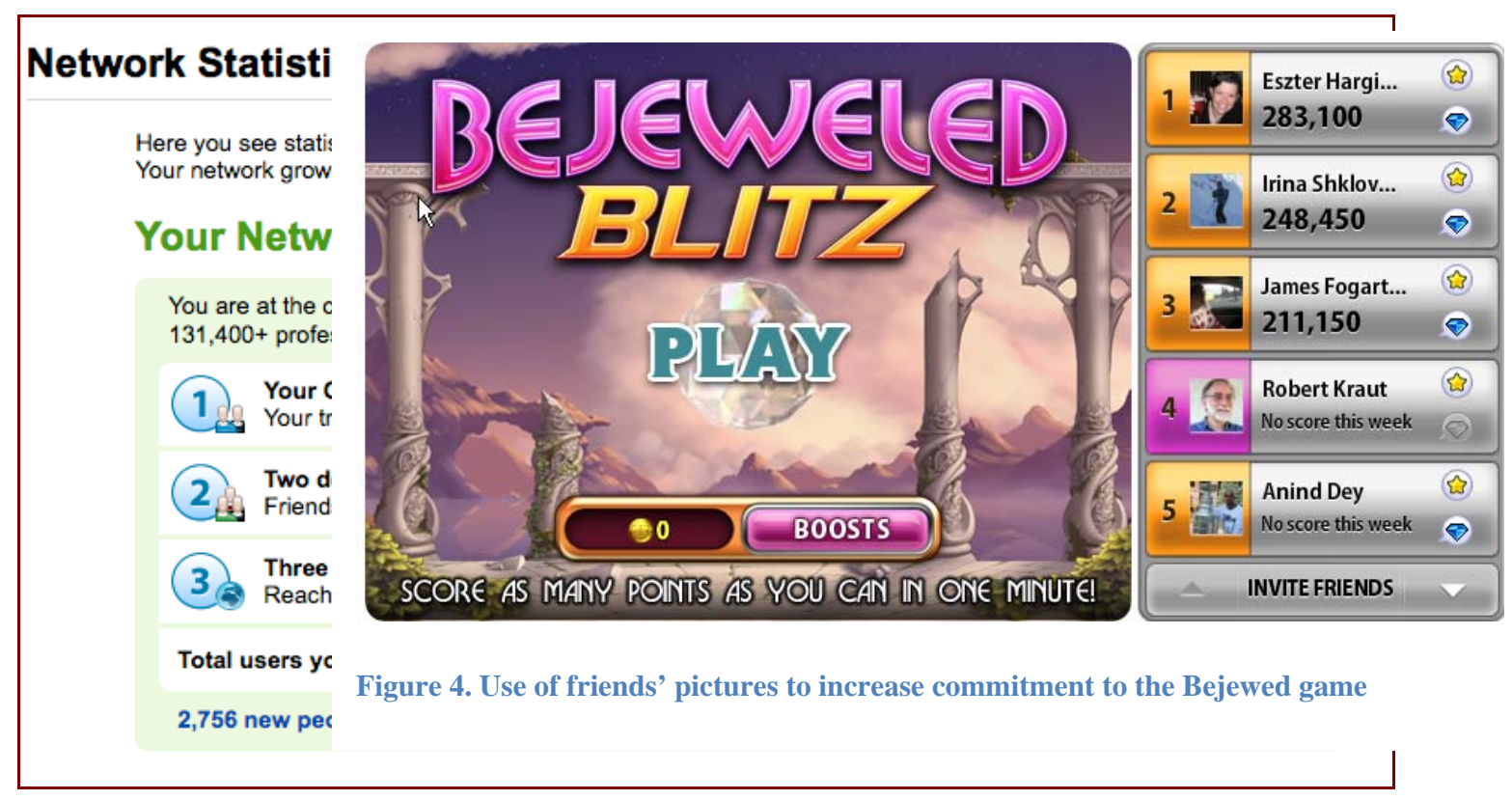

Figure 3. Linked-in's tools for seeing friends of friends

Design Claim 14. Facilitating interaction with "friends of friends" can enhance bonds-based commitment.

Another technique to foster bond-based attachment is to build features into the community that build and maintain new friendships among participants. Although psychologists have extensive theories about the factors that lead to interpersonal attachment (see Berscheid \& Reis, 1998 for a review), here we concentrate on factors that can be influenced by community designers and that have robust effects on interpersonal attraction: - repeated exposure, similarity, social interaction and self-disclosure.

As Milgram's discussion of the familiar stranger (1977) suggests, merely seeing other people in an online group repeatedly, even without communicating with these others, may be a precursor to forming a personal attachment to them. When applied to the challenge of increasing bondbased attachment to an online group, the implication is that designers should make the identity and behavior of the participants in the group known to each other. Seeing pictures of other people or even their avatars increases attraction, especially when people are just getting to know each other (Walther, Slovacek, \& Tidwell, 2001; Yee, Bailenson, \& Rickertsen, 2007)). Providing a stream of fresh information about the others enhances this familiarity effect.

Facebook does an excellent job of leveraging these principles. The home pages of many groups feature photos of a selected set of members, recent discussion posts, and photos, videos, and links shared by members. Even applications on social networking sites are often surrounded by pictures of users and fans. These images increase the likelihood that people will form an 
attachment to another member, even if they originally joined just to play a single-person game. (See Figure 4, showing the use of pictures of people to build attachment to the single-player game Bejeweled.)

Facebook incorporates the familiarity principle into its core features, such as its "what's on your mind" newsfeed features (See Figure 5). The typical homepage on Facebook.com shows frequently updated information and a constant stream of comments, videos, and activities of friends, continually reminding users of their friends' existence. Through these techniques, Facebook helps to build and maintain the bonds among friends and through this route keeps users attached to Facebook itself.

Design Claim 15. Displaying photos and information about individual members and their recent activities will promote bonds-based commitment

Social interaction is the primary basis for building and maintaining social bonds. The experience and familiarity we gain through social interaction with others increases our liking for them (Homans, 1958). Conversing with people and doing things with them provides opportunities for people to get better acquainted and to build trust. As the frequency of interaction increases, their liking for one another also increases (L. Festinger, Schacter, \& Back, 1950; Newcomb, 1961). Some studies have discovered an approximately linear relationship between liking of group members in small groups and frequency of interaction with them (Lott \& Lott, 1965).

In online communities, members' frequency of interaction with others is a major determinant of the extent to which they build relationships with one another (McKenna, Green, \& Gleason, 2002). More exchanges among community members, through private messages, for example, provide opportunities for members to create liking and trust. Utz's (2003) study of MUD players showed that the longer their involvement in the MUD and the more real-world contact they had with other members, the more they felt a bond with other players. Interpersonal connections become even stronger if members have a sense of virtual co-presence or a subjective feeling of being together with others (Slater, Sadagic, Usoh, \& Schroeder, 2000).

Design Claim 16. Providing opportunities for members to engage in personal conversation will increase bond-based commitment in online communities

In offline environments, physical proximity causes clustering of interpersonal interactions. That is, people nearby are likely to interact often. For example, students tend to form closer friendships with those they sit next to in class (Back, Schmukle, \& Egloff, 2008; Sykes, 1976) and are more likely to marry people who live in

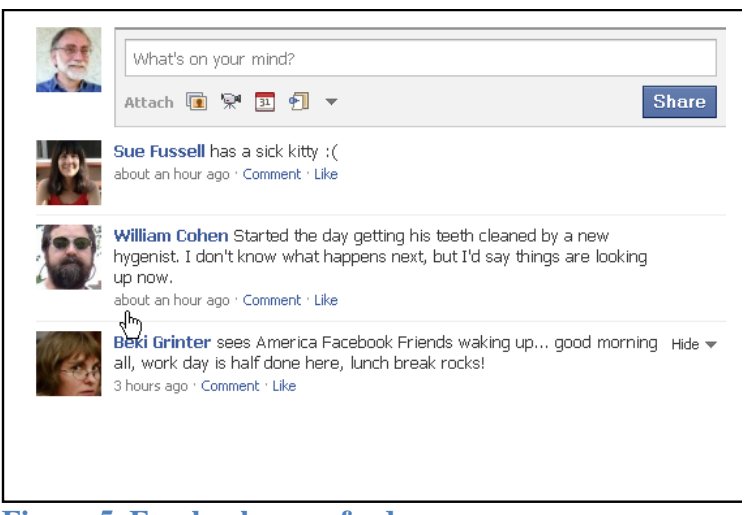

Figure 5. Facebook news feed the same neighborhood or go to the same school 
(Bossard, 1932).

Proximity is a reliable predictor of interaction, interpersonal attraction, and close bonds in many natural settings, such as boarding schools, college classes, large corporations, and housing projects (Newcomb, 1961).

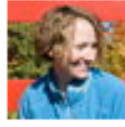

grammarnerd Women react differently the smell of men's sweat, depending on how it was produced (arousal, fear, normal conditions). http://bit.ly/bc/Nm9g 5:09 PM Jun 8th via web

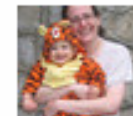
asbruckman Wiping Up After Online Universities: http://nextbison wordpress.com/2010/06/08/wiping-up-after-onlineuniversities/ 1:31 PM Jun 8th via TweetDeck

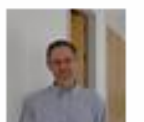

pfromthenc Why you should study the humanities: http:/nyti.ms laQGQpp. Bottom line: being able to read and understand and write clearly is power. 12:21 Plyl Jun 8th via TweetDeck

Figure 6. Following people on twitter

Online, there is no physical proximity to enforce clustering. Thus, it would be possible, in principle, for interaction pairings to be generated uniformly. Without sufficient repeat exposure, people would be less likely to form interpersonal bonds. Thus, designers need to create other mechanisms that generate clustering of interpersonal interactions.

One way is to create "neighborhoods" within the larger online community, in which a subset of the population can congregate. Online role playing sites, like World of Warcraft, use consistency of the server on which an individual subscriber plays the game as a device to insure that that the subscriber will repeatedly run into others assigned to the same server. In addition, these games typically have special communication features that alert them when other members of their marauding teams, known as guilds, are online and that allow them to broadcast communication exclusively to guildmates wherever they are in the sprawling virtual words they inhabit. The "rooms" in a traditional Multi-user Dungeons and Dragons site (MUDS) serve a similar function to increase repeated interaction among a subset of users. So, too, do separate topical forums or rooms in forum-based communities, and tag-based groups in the photo sharing site Flickr.

Content feeds based on already-articulated relationships also serve to generate repeated exposure and thus bonds-based attachment. For example, following people on Twitter (see Figure 6), friending them on FaceBook, , or subscribing to an RSS feed of their blog will lead to repeated exposure to that person's posts. Content feeds, however, can only strengthen ties that are already strong enough to have been explicitly articulated.

More sophisticated technical mechanisms are also possible that need not rely on spatial metaphors or bounded groups or previously articulated links. For example, software could automatically monitor which people someone has interacted with and highlight or sort new content in a way that makes people more aware of content from those they have interacted with already. While such mechanisms have been proposed (P. Resnick, Hansen, Riedl, Terveen, \& 
Ackerman, 2005) and implemented in research prototype systems (Ren, et al., Under review), we are not aware of any commercial online communities that have deployed them.

Design Claim 17. Places, spaces, groups, friend feeds, and other mechanisms that increase the likelihood that people will encounter the same people they have previously encountered will increase bonds-based commitment.

Self-disclosure-the exchange of personally revealing information--is both a cause and a consequence of interpersonal attraction. People not only like others about whom they know more, they like others to whom they reveal more (Collins \& Miller, 1994). Accordingly, members of online communities are more likely to form relationships if they have opportunities to self-disclose and learn personal details about each other. Opportunities for self-disclosure shift attention from the group as a whole to individual members (Tom Postmes, Russell Spears, \& Martin Lea, 2002; Kai Sassenberg \& Postmes, 2002).

Personal information not only increases people's liking for each other, but also increases their likelihood of interacting with them. It increases their ability to choose people they will trust and like. Knowing others' home towns and current residences enables members to identify those who live in the same region. They can then become real-life contacts. Likewise, the inclusion of contact information such as phone numbers, email addresses, and IM accounts enable members to connect and interact through other channels.

In online communities, any communication channel permits self-disclosure, but more structured technical and social features can encourage it. The most common feature is a user profile with personal information such as photos, background, experience, and interests that helps members know more about the people in the group. Many discussion-based communities include a forum or thread dedicated to self-introductions.

In a field experiment with a movie discussion community, we found that members with access to individual profiles with information about others' history, location, and movie preferences visited the site more frequently than those that did not have access to individual profiles (Ren, et al., Under review). For individual profiles to lead to commitment, however, designers need to be thoughtful about what fields to include and what information to encourage. For example, at professional social networking sites like LinkedIn, it is more meaningful to include fields related to people's professional experiences such as education and work experiences whereas at a movie discussion site, it is more meaningful to include fields related to people's movie tastes.

There is evidence that personal information, such as pictures, promotes interpersonal bonds among people who have not yet interacted (Walther, et al., 2001). Compared to strangers, people who were able to see another's online Facebook profile before conversing with them caused their partner to like them more by engaging in more effective small talk and self presentation (Hancock, Toma, \& Fenner, 2008).

Design Claim 18. : Providing user profile pages and flexibility in personalizing them will increase self-disclosure, interpersonal liking and thus bond-based commitment. 


\title{
Two truths and a tall tale
}

\author{
One of these three is not true; can you guess which? Please vote... \\ Rev. Jesse Jackson once told me to 'play another' song \\ My favorite vacation ever was to Brazil

True $\quad \boldsymbol{}$

False $\quad-$ \\ In grad school, I sometimes woke up at 4AM because I was so excited to get back Select ... - \\ to programming on my thesis project
}

I"m not sure what this says about the "wisdom of crowds". Collectively, people seemed to have no idea which of the three was false, although a few more seemed to think that Brazil was false than the others. They were right. I"ve never been to Brazil -- PaulResnick - 12 Dec 2005

Figure 7. An online ice breaker

Somewhat paradoxically, revelation of personal information may actually increase if the most personal information, one's true identity, is hidden. For example, in the fitness and weight loss community SparkPeople, many people use pseudonyms rather than their real names, but reveal quite detailed information, including daily weigh-ins. In their blogs, they also reveal their struggles and difficulties as well as triumphs. In interviews, people who used FaceBook and SparkPeople said that they felt much more comfortable revealing detailed personal information on SparkPeople, where that information could not be associated with real-life identities or easily found by the their real-life friends.

Design Claim 19: Allowing participation under a pseudonym will increase self-disclosure, interpersonal liking and thus bond-based commitment, in communities where sensitive information is shared.

One surprising finding from the psychological research is that people like others to whom they disclose personal information (Collins \& Miller, 1994). In off-line conversation, people know to whom they have revealed information about themselves, but this awareness of the audience isn't necessarily the case online. Since the effect of disclosure may be stronger when people know who they have disclosed to, an automatic report about who has read one's profile or a social convention of leaving a "guest book" entry or comment, could enhance feelings of closeness from self-disclosures.

While personal profiles permit people to learn about others, they do not facilitate self-disclosure as a communicative act, a decision to reveal particular information to particular others in particular circumstances. It is likely that the decision to reveal oneself to others is what makes one like them and not just their possession of the information. Moreover, the act of sharing generates a reciprocal obligation to self-disclose that may not be triggered by simply seeing information in someone's user profile.

Some online community moderators have a deft touch at asking questions that lead member to self-disclosure. For example, in a forum for people participating in a pedometer-based walking program, a moderator posted a question about fitting in exercise during a sister's graduation 
weekend. Perhaps because it was self-revelatory, it led to self-revelatory responses from other group members (Paul Resnick, Janney, Buis, \& Caroline R Richardson, in press). Other, more structured ice-breaker activities and games are possible. For example, in our research group we once added an ice-breaker game to our on-line profile pages. Each person posted three interesting personal stories, only two of which were true, and everyone had to vote on which was the tall tale (see Figure 7). People revealed personal stories that had not come up in our usual interactions. One intriguing option that we have not yet seen explored would be to have people interactively choose profile fields to reveal to particular others. This might be especially effective in an online dating site, where each act of disclosure would signal a continuing interest based on the interactions up to that point.

Design Claim 20. Active self-disclosure with visible response will lead to more bonds-based commitment than will passive disclosure.

Just as people like groups whose focus seems similar to their own interests and goals, they also like other people who are similar to them in preferences, attitudes, and values, and they are likely to work or interact with similar others. In his pioneering longitudinal study of college students, Newcomb (1961) found that high interpersonal attraction developed among those who initially had attitudes in common. Experimenters frequently manipulate similarity in dyads to increase their liking of each others (Byrne, 1997). In research on groups, they manipulate similarity among group members to vary group members' attachments to each other. Typically, participants completed a personality and friendship questionnaire and were told that they were assigned to a group whose members probably would become close friends (M. Hogg \& Turner, 1985; T. Postmes, et al., 2001). When similarity was presented as the sharing of unique personal attributes between the self and other members, but not necessarily an in-group prototype (e.g., unique movie tastes or personal preferences of celebrities), it triggered bonds-based attachment with the target being idiosyncratic individual members who could not necessarily be replaced with any other group member (M. Hogg, 1992, p. 100). Figure 8 shows a "compatibility" report comparing the movie tastes of two members of the MovieLens site. 


\section{Design Claim 21. Highlighting interpersonal similarity will foster closeness among individual members and bond-based commitment.}

\subsection{Reducing repelling forces that undercut personal commitment}

People feel more committed to smaller groups than larger ones (Carron \& Spink, 1995). One reason is that interpersonal bonds are difficult to maintain with a larger number of individuals. When people relate to others, they devote time and attention to them. Thus people are only able to maintain a limited number of strong ties with others. The anthropologist Robin Dunbar (1993) proposed that humans evolved having a cognitive limit, on average 150, to the number of individuals with whom they could maintain close, stable relationships. (Of course, this number varies across different people. Extraverts know more people than do introverts, and they spend more time communicating with others, seeking out relationships, and engaging in social events.) Even though social networking sites have greatly expanded social circles and reduced the cost of maintaining weak ties (Granovetter, 1973), these sites do not necessarily increase the number of close ties people have. As of June, 2010, the average Facebook active user maintained ties to 130 friends on the site ${ }^{4}$. Similarly, Figure 9 shows that most guilds in game of Ultima Online had fewer than 135 members, with 60 being the mode.

\footnotetext{
${ }^{4}$ http://www.facebook.com/home.php?\#!/press/info.php?statistics
}

Movies You Agree On

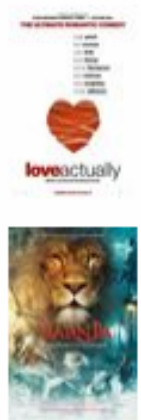

Love Actually

Nikhila:

The Chronicles of

Narnia: The Lion, The

ardrobe

You: काजी

Nikhila: thenth

Match: Exact

Figure 8. Compatibility report for MovieLens
Movies You Disagree On

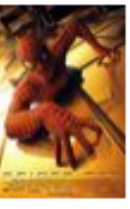

Spider-Man

You:

Nikhila:

Match: Very Bad

Charlie and the Chocolate Factory

You:

Nikhila:

Match: Bad

\section{Movie Compatibility Report}

3-Ren10-Commitment 0912v10-Ss.Doc last saved 11/30/10 
Another reason for the preference for smaller groups is that when many people are communicating, each pair may not have enough repeated interactions for bonds to form unless, as indicated previously, some mechanism is in place to cluster people. For example, the movie site IMBD hosts messages from thousands of people. Posts arrive in such quantity that a new post remains on the front page for less than 20 minutes. Under these conditions, it will be difficult for pairs of people to come across each other frequently enough to form bonds. In one analysis of a large sample of Usenet newsgroups, the more messages posted in a group during a month, the smaller was the proportion of posters who returned in the subsequent month (Jones, Ravid, \& Rafaeli, 2002). Although email-based listserv communities attracted more new members per month if they were larger, those with more traffic had higher turnover rates (Butler, 2001).

Larger community size and communication volume do not limit identity-based commitment in the same way. Identity-based commitment does not depend on repeated communication or personal ties with specific other members. In principle, with identity-based commitment, individual other members are interchangeable representatives of the community. This reasoning is consistent with a a field experiment in a movie discussion community, where use of algorithms to repeatedly expose individuals to movie groups led to a significant increase in member commitment to these groups whereas the same algorithm to repeatedly expose individuals to familiar others did not have such an effect (Ren, et al., Under review).

Design Claim 22. Large communities with a large volume of communication reduce bonds-based commitment, unless some means of clustering communications is used

Most people feel psychologically safer when a community's membership is more homogeneous than when there is a diversity of member backgrounds and views. Membership diversity can lead people to feel there may be less coherence of community purpose than

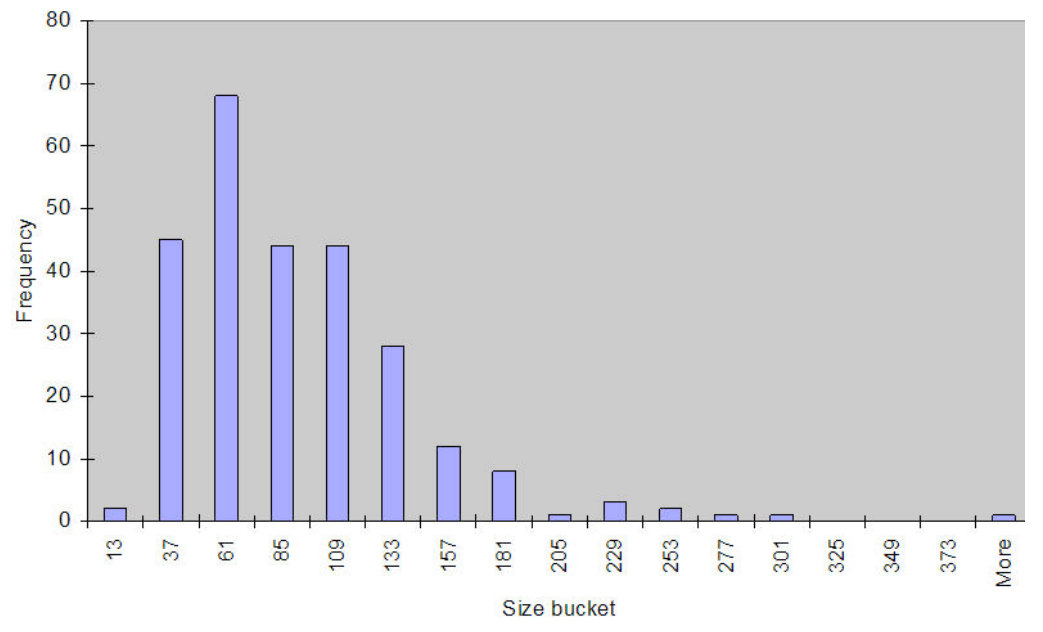

Figure 9. Histogram of Ultima Online game guild size distribution (active members only).

they would like and a fracturing of community communications. The growth of a community can lead to more diversity of membership than the community had in the past, if only because new cohorts are younger, with different concerns than older members have. Such diversity of membership attributes can threaten people's sense of common social identity and lead to turnover in groups (Williams, 1998). New cohorts are likely to differ from oldtimers not just in 
their personal attributes but also in attitude and motivation. For example, when Systers, a listserv for female mostly university-based computer scientists, started recruiting many younger women, the newcomers were more likely to be employed by industry and to be interested in success in that nonacademic domain. Many older Systers left, and a new effort had to be mounted to keep the community going (Jeffries, Kiesler, Goetz, \& Sproull, 2000; Spertus, Jeffries, \& Sie, 2001).

Design Claim 23. Diversity of members' interest in an online community can drive away members, especially those with identity-based commitment

A special problem of diversity among member interests is the management of off-topic conversations, that is, conversations that are irrelevant to the main purpose of a community, such as political comments or revelations about personal experiences in a movie discussion group.

Community designers must decide whether to try to keep discussion on-topic or to let it stray. (Chapter xxx, on regulating behavior, discusses ways to keep discussion on-topic, if that is desired.) Many topical discussion communities discourage off-topic communication. For example, the introductory message to Joblo's Movie Club emphatically states, "Our board is for MOVIE TALK only. If you bring personal issues up on our board, you will be banned. If you discuss your ex-girlfriend, you will be banned. If you announce your comings and goings or gossip about so-and-so, you will be banned. ... This is ... not a place for you to discuss your personal life or boo-hoo about how your lover just broke up with you (Joeblo Movie Club, 2005)." On the other hand, in the newsgroup X-Fileaholics, whose nominal topic is discussion of the TV show X-Files, it is normal for members to discuss everything but the show, including favorite music, other television shows or movies, humorous polls, unpleasant events, and recent achievements. Newcomers, in an official welcome message posted within the joining thread, are encouraged to "act demented [because] it runs in the family (Honeycutt, 2005).” One study found that 36\% of Q\&A threads on Yahoo! Answers were "conversational” rather than “informational” (Harper, Moy, \& Konstan, 2009).

A community's policy to either constrain or open up content has tradeoffs that designers need to address. Off-topic conversation, by distracting from the unifying feature around which people identify, reduces identity-based commitment. But it can help a subset of individuals discover additional common interests, beyond those defining the community, and allows them to share personal information, thus enhancing interpersonal bonds. The kind of self-disclosing conversation that we previously argued builds bonds is off-topic. An empirical investigation confirmed that restricting conversation to specific domains make a site less appealing to people who want to know individuals better, whereas a policy of encouraging off topic conversation can undercut identity-based attachment (Tom Postmes, et al., 2002).

Design Claim 24: Off-topic communication will reduce identity-based commitment, but increase bonds-based commitment to an online community.

Sometimes a community that forms for one purpose will temporarily shift its focus due to special circumstances. For example, following the Pacific Tsunami in December 2004, a knitting hobbyist who went by the screen name of "Yarn Harlot" started publicizing a "Knitters Without Borders" challenge in knitting groups she participated in. She has tracked more than \$1 million 
in donations to the organization "Doctors Without Borders"5. Around the time of an election, some groups that normally do not discuss politics do so.

We have coined the phrase, "going off-topic together" to describe situations where something that would normally be considered off-topic (such as fundraising or politics) becomes on-topic, at least temporarily. Going off-topic together can build both bonds-based and identity-based attachment. Bonds can form because people see another side of each other that was not revealed in previous interactions. Whereas previously identification with the group was primarily through identification with the topic, going off-topic together creates an opportunity to identify with the group of people separately from the topic. Although we use the term online community broadly in this book, in classes we find that some students prefer to reserve that term for groups with affective ties and multiplex relationships, akin to close-knit geographic neighborhoods. Given that distinction, going off topic together is one marker for when a group has truly become a community.

Design Claim 25: Going off-topic together can increase both bonds-based commitment and identity-based commitment.

A flexible approach to off-topic conversation could serve both needs for identity and bond-based commitment. A computer simulation model by Ren and Kraut (Ren \& Kraut, Under review) suggests that personalized filtering, in which people in a community are exposed only to communications that match their interests, will lead to greater commitment than regimes that do not moderate communicate at all or moderate it so that off-topic messages are removed for all community members. According to the simulation, these positive effects of personalization seem to be strongest in larger groups or groups encompassing a diversity of topics, and support both identity-based and bond-based attachment.

A number of approaches can be used to personalize the content of a site. The simplest is to provide separate areas for on-topic and off-topic conversation. Many topic-based communities, such as the movie web-forum RottenTomatoes (rottentomatoes.com/vine) and the CNET site for equipment reviews (reviews.cnet.com), provide separate off-topic discussion boards. The "Off Topic Discussion" forum on the Rottentomatoes.com site and the off-topic "Speakeasy" forum on the CNET site are highly popular. Having separate areas for off-topic conversation has the drawback of segregating it, so that it is seen only by those who explicitly decide to view it. People may need to already have bonds-based connections with others in order to want to visit the place where bonds can form.

Online communities can also identify off-topic content without segregating it, for example, by using tags. When traffic expanded in the online soap opera newsgroup rec.arts.tv.soap, people started complaining about messages that were unrelated to soap operas. Some members proposed marking messages that were not directly related to soap operas by "TAN" (for tangent) in the

\footnotetext{
${ }^{5}$ http://www.yarnharlot.ca/blog/tsffaq.html
} 
subject line so that members who were not interested could easily ignore them, while preserving them in the group for those who were interested (Baym, 1999). Information retrieval techniques (Foltz \& Dumais, 1992; e.g., Landauer, Foltz, \& Laham, 1998) can be used to estimate how similar a focal message is to other messages recently posted on a forum, and readers can decide to view messages of different relevance. An administrator of an identity-based site could set a threshold to can visually differentiate the off-topic content. Or make it more difficult for newcomers to see.

Design Claim 26. Personalized filters, which differentially expose members to communications that match their personal interests, will reduce the negative effects that off-topic communication has on identity-based commitment

\section{Normative Commitment}

Normative commitment is a feeling that one has obligations to the community to be loyal and act on its behalf. Many factors can contribute to creating normative commitment to a community. Here we consider three: commitment to the cause, others' normative commitment, and reciprocity.

One reason people feel a normative commitment to an online community is because they have a pre-existing commitment to the purpose that the community serves. This may be a stronger resource for generating commitment in advocacy communities and production communities than in hobbyist communities. Thus in open source software development projects, having common values about the importance of sharing and helping each other predicts group members having commitment to the group, which in turn predicts the effort they contribute (Stewart \& Gosain, 2006). .But even in hobbyist and support-oriented communities, people may feel a strong commitment to advancing the hobby or helping people suffering from a particular health condition or life circumstance. To translate normative commitment to a community's purpose into commitment to the community itself, the community will need to keep its purpose salient throughout its activities and show that it is having some success in achieving its purpose. For example, open source communities would want to highlight statistics and stories about how useful the software is and how important are the next version's planned improvements.

Design Claim 27. Highlighting a community's purpose and successes at achieving that purpose can translate members' commitment to the purpose into normative commitment to the community

Another reason people accept a normative obligation is if there is a shared norm about that obligation. For people who are unsure whether something is a shared norm, social proof that others believe it is can help resolve the uncertainty. In other chapters, we point out the power of social proof about the value of joining a community and norms of good behavior. Here, we argue that demonstrations that others feel a normative obligation to the community are a powerful way to spread that feeling of obligation. Since it is not so much actions as feelings that are to be demonstrated, the most effective means are likely to be narrative testimonials. Raymond points out the moral obligation that participants in opens source software development projects have to help each other "To behave like a hacker, you have to believe that the thinking time of other

3-Ren10-Commitment 0912v10-Ss.Doc last saved 11/30/10 
hackers is precious - so much so that it's almost a moral duty for you to share information, solve problems and then give the solutions away just so other hackers can solve new problems instead of having to perpetually re-address old ones.(Raymond, 2003, December 29)” These types of quotes could be honored, whether offered by community leaders or regular members during the regular course of conversation.

Design Claim 28. Testimonials about people's normative commitment to the community will increase others' normative commitment

A third generator of normative commitment is the widely shared norm of reciprocity. Reciprocity is one of the strongest and most university of human norms (Gouldner, 1960). People think that those who have given should get something back and those who have received should give something back. Researchers have distinguished between direct reciprocity, where people feel obliged to help particular others who have helped them, and indirect or generalized reciprocity, where people feel obliged to "pay it forward" to somebody, even if it's not the specific person who helped them (e.g., Nowak \& Sigmund, 2005; Yamagishi \& Kiyonari, 2000). These feelings of obligation are one reason that cancer survivors or caregivers in online support groups continue to participate, offering advice to others, even after their own cancer is in remission or after the person they had cared for has died. Researchers have argued that this indirect reciprocity is critical to the development of human group and society more generally, and that people will forego their own economically rational self-interest to punish those who don't reciprocate (Fehr \& Gächter, 2000).

Designers can prime the norm itself, making it more salient, by using language such as "reciprocity”, “obligation”, “giving back”, “paying it forward” or terms that otherwise active altruistic motivations. Psychologists have found that priming, even unrelated to the specific context of action, can have surprisingly strong effects on people's actions in laboratory settings. For example, compared to subjects in a word recognition experiment who saw neutral words, those who saw words with a positive religious tone (e.g., heaven, faith) were willing to distribute twice as many pamphlets to help a charity (Pichon, Boccato, \& Saroglou, 2007).

Design Claim 29. Priming norms of reciprocity by highlighting concepts that get people to think of their normative obligations should increase normative commitment to an online community

More directly, designers can highlight what individual members have received from a community. An experiment on the movie recommendation site gave people feedback about their "net benefit" score, estimated from their previous activity. Subjects told that they had aboveaverage net benefit scores were more likely to select additional activities that benefited the community rather than benefiting themselves (Y. Chen, Harper, Konstan, \& Li, In press). Similarly, rather than providing a strict accounting, designers can highly more general benefits that members receive. For example, Jimmy Wales, founder of Wikipedia, is emphasizing 
generalized reciprocity when he says, Wikipedia "stopped being just a website a long time ago. For many of us, most of us, Wikipedia has become an indispensable part of our daily lives." 6

Design Claim 30. Showing people what they have received from the community will increase their normative commitment to it.

Perhaps even more powerfully, designers can also invoke a direct reciprocity norm. For example, the open-source project Drupal has a bottleneck on incorporating new code contributions:

members are contributing code faster than it is getting reviewed. This is frustrating to the coders whose patches are left in limbo, and inefficient for the project as well. We are working with the community to design a feature that will highlight code patches awaiting review that were written by people who have previously reviewed your code. We expect that people will feel an obligation to help others who have helped them, and will thus spend more time reviewing their code.

Design Claim 31. Highlighting opportunities to return favors to specific others will increase normative commitment to the community

\section{Needs-based commitment}

${ }^{6}$ http://wikimediafoundation.org/wiki/Support_Wikipedia/en 
Needs-based (or continuance) commitment refers to attachment to an online community that depends on the net benefits people's experience from the community. According to needs-based models of social cohesion, people stay in a group only as long as they perceive the group and other members as being attractive and instrumental in fulfilling their personal goals (Homans, 1961). When net benefits are positive, members predict that they get sufficient rewards to warrant the time, effort, and frustration they spend on the community. When benefits are low and the costs of leaving the community are low, commitment will also be low. Although most research suggests that these direct they personally receive from the community are not the only source of commitment, most members do care about these benefits. These benefits include information, social support, companionship and reputation, among others (Ridings \& Gefen, 2004). The importance of these benefits vary across both different types of communities and different individuals. For example, Ridings and Gefen (2004) asked almost 400 participants in 27 online discussion groups why they joined. As seen in Figure 10, members of most types of communities valued getting information. However, health and wellness groups were differentially less interested in information and more interested in social support, while those in many hobby groups were disproportionately interested in companionship. In a discussion group for legal professionals, many members commitment were motivated by the perceptions that participation in the group would lead to enhanced regulation (Wasko \& Faraj, 2005). In many gaming communities like World of Warcraft, members' commitment is motivated by the challenge and fun the game provides as well as the opportunities to hang out with friends (Ducheneaut \& Moore, 2004; N. Ducheneaut, N. Yee, E. Nickell, \& R. Moore, 2006; N. Ducheneaut, N. Yee, E. Nickell, \& R. J. Moore, 2006). Owners and moderators of voluntary discussion groups tend to be less motivated by getting information and more interested in friendships and other social benefits (Butler, Sproull, Kiesler, \& Kraut, 2007). As we discuss

\begin{tabular}{|l|r|r|r|r|}
\hline & \multicolumn{4}{|c|}{ Motivational Category } \\
\hline $\begin{array}{l}\text { Community } \\
\text { Type }\end{array}$ & $\begin{array}{c}\text { Info. } \\
\text { Exchg }\end{array}$ & $\begin{array}{c}\text { Companion- } \\
\text { ship }\end{array}$ & $\begin{array}{c}\text { Social } \\
\text { Support }\end{array}$ & \multicolumn{1}{c|}{ Fun } \\
\hline Professional & $53 \%$ & $11 \%$ & $22 \%$ & $10 \%$ \\
\hline Health & $38 \%$ & $17 \%$ & $38 \%$ & $4 \%$ \\
\hline Hobby & $52 \%$ & $29 \%$ & $2 \%$ & $9 \%$ \\
\hline Sports & $58 \%$ & $18 \%$ & $4 \%$ & $11 \%$ \\
\hline Pets & $48 \%$ & $36 \%$ & $3 \%$ & $9 \%$ \\
\hline Other interests & $53 \%$ & $26 \%$ & $0 \%$ & $9 \%$ \\
\hline Overall Percentage & $50 \%$ & $24 \%$ & $11 \%$ & $9 \%$ \\
\hline \multicolumn{1}{|c|}{ Total N (reasons) } & 257 & 124 & 56 & \multicolumn{1}{c|}{45} \\
\hline
\end{tabular}

Figure 10. Reasons for joining different types of discussion groups (from Ridings and Gefen, 2004) 
more in the chapter on newcomers, participants who do not perceive the community as providing the benefits they desire are especially likely to leave.

To design experiences that meet members' needs requires knowing what these needs are. If you don't know what members want, then it is hard to satisfy them. Sometime the members' motivations are not obvious, even to insiders. For example, even though most developers who participate in open source software development projects do so for instrumental reasons (i.e., to get better code or a better job) or for identity-based ones (e.g., to feel part of social movement they consider ideologically important), some also want to develop friendship with other developers they meet online. To satisfy this need, some open source development projects host 'code fests', where developers can meet each other and form relationships. For example, The GNOME software project, a graphic desktop for the Linux operating system, hosts the GNOME Users' And Developers' European Conference, whose motto

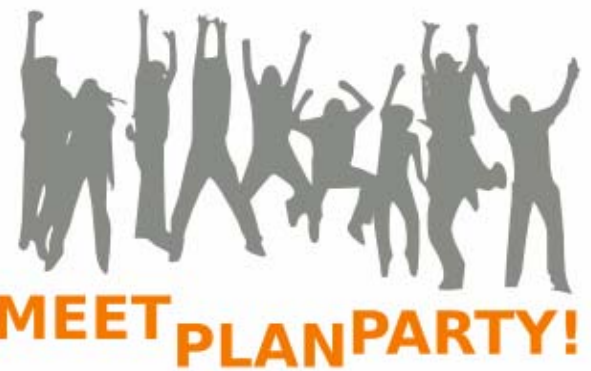

The GNOME Conference 2008 Figure $\mathrm{X}$ :

Figure 11. Logo for the GNOME Users' And Developers' European Conference

(http://guadec.expectnation.com/) is 'Meet, Plan, Party!'.

Some research has developed validated survey instruments and other techniques to assess the motivations of volunteers in conventional organizations, such as altruism, career or social contact (Clary, et al., 1998). Matching recruiting materials and experiences with the reasons that particular people volunteer increases their willingness to join, their satisfaction and their willingness to continue in the organization(e.g., Crain, Omoto, \& Snyder, 1998; Williamson, Snyder, \& Omoto, 2000, May). These general survey instruments can be adapted to use in assessing motivations in online communities. In addition, others have developed survey instruments to assess motivations for participating in online communities, such as open source development projects (Ghosh, 2005) and Wikipedia (Nov, 2007). By understanding the profile of motivations of participants in an online community, designers are better able craft experiences that match these motivations

Design Claim 32. Providing participants with experiences that meet their motivations for participating in the community will increase their needs-based commitment to the community 
As with interpersonal relationships, the net benefit that people need to achieve to decide to stay in a community depends upon the alternatives that are available (Thibaut \& Kelley, 1986). Simply put, people will be satisfied with fewer benefits and will tolerate more some of the unpleasantness associated with any group membership when they have fewer alternatives available. For example, employees are less likely to quit their company when there are fewer equivalent jobs available (e.g., Hulin, Roznowski, \& Hachiya, 1985). In the online world, people stay in Usenet groups long if there are fewer Usenet groups in the same ecological niche-e.g., serving similar content (Wang, 2007). The implication is that to build needs-based commitment, an online community must meet the needs of its members more when it has many competitive than when it has few. Although community designers cannot control its competition, they can raise or lower the visibility of these alternatives when members are actually participating in the community. For example, including links to competing communities increases the ease with which a member can deflect, by clicking competitors' sites. Wang (2007) found that the more cross-posted messages (i.e., messages that also were posted to competitor groups) were displayed in a Usenet group during a month, the more quickly members defected from the group. Some online communities do post links to competitions. For example, the Advanced Breast Cancer Community (advancedbreastcancercommunity.org) posts links to its main competitors, including CancerCare and the Cancer Support Group, while these latter groups do not (see Figure 12).

Design Claim 33. Showing information about other communities in the same ecological niche reduces needs-based commitment

Some online communities try to supplement the psychological benefits members derive that come from fulfilling motivation with specific benefits for those who participate and contribute. For example, epinions.com offers profit sharing; Slashdot.com offers recognition, and

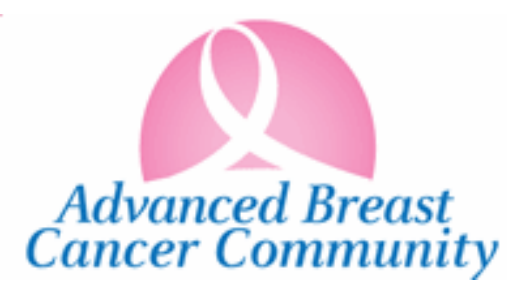

\section{Online Support}

- Join our AdvancedBreastCancerCommunity.org Support Community

The only online community focused exclusively on advanced and metastatic breast cancer. Registration required.

- Online Support Groups - Cancercare

Online support groups can be accessed whenever you need them, 24 hours a day, 7 days a week facilitated by a professional oncology social worker

- Join a Cancer Support Community Online Support Group - The Cancer Support Community (formerly The Wellness Community)

A facilitated private online support group — registration is required.

Figure 12. Showing links to competitors reduces needs-based commitment. 
Coolsolutions.com offers T-shirts that symbolize that the wearer has made a meaningful contribution (Tedjamulia, Dean, Olsen, \& Albrecht, 2005). Many sites offer ratings, status, or points to reward contributions. According to some researchers, these direct rewards for contributions can rob people of the intangible pleasure they get from contributing and their sense of identity with the community (Deci, Koestner, \& Ryan, 1999), but other researchers believe direct rewards can usefully supplement psychological incentives (Cameron, Banko, \& Pierce, 2001; Eisenberger, Pierce, \& Cameron, 1999). We consider the tradeoffs of offering direct rewards below.

A variant of needs-based commitment, sometimes referred to as lock-in (Shapiro \& Varian, 1999), occurs when members accumulate community-specific assets that retain their value only through continued participation in the community. These assets can include resources in the community, both people and content. For example, the friends one is connected to on Facebook are an asset, producing value when one continues to use Facebook. The status and privileges one has accumulated are also community-specific assets. For example, in World of Warcraft, players can buy a mount to transport them rapidly across the landscape only after they have completed enough quests to reach level 40 in the game and have accumulated the price of the mount in ingame gold. Once acquired, the steed is a community-specific asset. One's historical data with a set can also be an asset. For example, the ratings one has entered in a recommender site, like Netflix or movielens.org, or the financial information one has posted in financial sites like vanguard.com or intuit.com are also community-specific assets, that improve service quality. In a study of turnover in customers' user of online brokerage sites, Chen and Hitt (2003)showed that established customers were less likely to leave compared to new customers when sites provided relationship services, which included personalizing data, reusing customer data to facilitate future transactions, using customer data to support business or personal needs such as filing taxes, and allowing a customer to customize the site. A controlled experiment on eBay showed that an established history or reputation was an asset worth about $8 \%$ in additional revenue for a seller (P. Resnick, Zeckhauser, Swanson, \& Lockwood, 2006).

To generate needs-based commitment, an asset has to be difficult for a member to transfer to a new community. The chapter on starting a new community discusses the advantages of importing resources of various kinds from external sources. To keep members locked-in, however, it can be helpful to limit exports. For example, Facebook makes it difficult to export friends lists or accumulated personal information such as profiles. Netflix does not provide a history of one's ratings in a format that is easily exported to other move recommending sites. Similarly, because Amazon does not allow a customer to export her own purchase and shopping history, only Amazon can provide useful customization based on that history. Similarly, eBay has not participated in open reputation systems that would allow reputations built on eBay to be used (and put at risk) on other sites.

Skills are an interesting special case of a community-specific asset. Members learn technical skills at operating a community's software, as well as social skills of effective participation. To the extent that the software, modes of interaction, and social etiquette are unique, learning them creates a community-specific asset. Indeed, Chen and Hitt's study showed (2003) more turnover 
in sites that were easier to use, presumably because ease of use reduced customers investment in learning how to use the site.

To generate needs-based commitment, an asset also has to be difficult to transfer to another member. Otherwise, a member may be able to sell assets when leaving the community, and the assets would not create the same lock-in. Thus, developers of multiplayer games put policies in place to depreciate the value of these accumulate assets if players leave. Selling in-game currency, loot, or other virtual items for real money is against the terms of service for most multi-player games. In 2006, Blizzard, the company operating World of Warcraft band or suspended over 15,000 accounts for selling virtual property ${ }^{7}$. The operators of multi-player games persuaded the on-line auction house eBay to delist auctions for virtual items ${ }^{8}$.

Design Claim 34. Making it difficult for members to export assets or transfer them to other members increases needs-based commitment

Members' community-specific investments that cannot be recouped when they leave can generate commitment even when those investments are merely sunk costs that do not create any value going forward. For example, even if a member has not yet found the upper levels of a multi-player game particularly enjoyable, she may remain committed to the game because of the extraordinary efforts she has already invested to reach those levels.

From a purely rational cost-benefit analysis, such sunk costs, once incurred, should have no influence on members' choices. Yet they frequently do (Arkes \& Blumer, 1985). One reason is heuristic processing: when it is not clear how valuable an asset will be, a larger investment made to acquire it can be interpreted as an indicator of its value. A second reason is cognitive dissonance (Leon Festinger, 1957): people need to believe that their previous investment decisions were good ones, so they make further choices that could result in justifying the earlier ones. Arkes and Hutzel (2000) demonstrated in lab experiments that at least some of the reason sunk costs influence future choices comes from the latter effect. Consistent with this explanation, experimental research demonstrated that people like groups more if they have to endure a severe initiation process to join them than if they undergo a milder initiation (Elliot Aronson \& Mills, 1959; Gerard \& Mathewson, 1966). According to Aronson, people come to like things for which they suffered, because this is the only way they can reconcile their views of themselves as intelligent people with the actions they have performed (E. Aronson, 1997).

In an online community context, Drenner and her colleagues (2008) introduced effortful barriers to the online movie recommender site,

\footnotetext{
${ }^{7}$ http://www.gamasutra.com/php-bin/news_index.php?story=i

${ }^{8}$ http://games.slashdot.org/article.pl?sid=07/01/26/2026257
}

3-Ren10-Commitment 0912v10-Ss.I

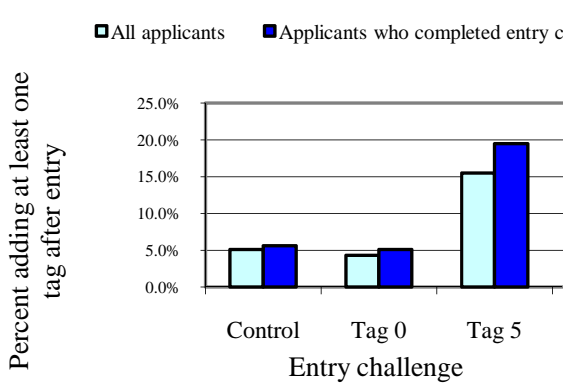

Figure 13. Effects of entry barriers on post-entry contributions to Movielens (from Drenner, et al, 2008) 
Movielens.org. All users of the site were asked to rate five movies, to let the site know about their movie tastes. Some new registrants were in addition required to apply 25 descriptive text tags to movies before they were allowed to register (Tag 25), some had to apply five tags (Tag 5), some were simply shown the tagging interface but not required to tag any movies (Tag 0), and some were not even shown the tagging interface (Control). As expected, as the amount of work required in the registration process increased, the proportion of registrants who completed the full registration process declined, from $90 \%$ completion in the control condition, to $85 \%$ Tag0 condtion, $80 \%$ in the Tag- 5 condition to $69 \%$ in the Tag- 25 condition. More interestingly, new users who were assigned to do more work as part of their registration process were four times more likely to provide tags once they become members and contributed over 10 times the number of tags as those in the control condition. The effects were only partly the result of the type of we discussed previously. As the light-colored bars in Figure 13 illustrate, the effects of the entry barriers were strong even when considering all potential members exposed to them, not just to those who surmounted them.

In an open source community, requiring programmers to complete many bug fixes before earning full membership privileges has two effects. In the chapter on newcomers, we point out that such a requirement serves as a screening mechanism, weeding out potential members who are not a good fit for the open source project. But it may also act as an initiation rite, increasing the commitment of those who attain those privileges. Of course, any requirement of time investment is a double-edged sword: it increases commitment (and fit) among those who make the investment but may drive away some potentially valuable members who are unwilling to make the initial investment.

Design Claim 35. Entry barriers and other opportunities for members to make communityspecific investments, even if they are merely sunk costs that do not create valuable assets, will increase need-based commitment.

\section{Summary of Design Alternatives}

As in other chapters, we conclude with a table of the design alternatives considered in this chapter, and an index to the design claims that discuss their implications. The chapter examined the challenge of increasing commitment to online communities. Commitment enhances a community's ability to surmount other challenges - getting newcomers to stick around, getting members to contribute, and encouraging community members to behave appropriate. Scholars have identified several types of commitment to groups and organizations: affective commitment based on common identity or interpersonal bonds, normative commitment based on feelings of obligation and needs-based commitment based on perceived benefits for staying and the costs of leaving. We conclude by inverting that focus. We reflect on the design space of alternatives and the ways that alternative designs affect the various types of commitment.

Some design alternatives affect the membership composition of the community, or its substructure. For example, diversity of members' interests can reduce identity-based commitment; one way to combat that is to limit diversity, either in the group as a whole, or in 
subgroups. Recruiting participants based on existing ties can also enhance bonds-based commitment. Larger communities with a large volume of communication limit bonds-based commitment; subdividing into smaller groups can help. Naming those subgroups can help generate identity-based commitment as well.

The next group of design levers changes the content or activities that are available in the online community. Interdependent tasks can enhance identity-based commitment. Interactions with "friends of friends" can enhance bond-based commitment, as can displaying photos and profile pages and offering opportunities for personal conversation and personal information revelation. Off-topic conversation can enhance bond-based commitment, but interfere with identity-based commitment. Activities that generate community-specific assets that are difficult to export or transfer can build needs-based commitment.

Designers can also build commitment through clever selection, sorting, and filtering of the content that is displayed to people. Creating repeated exposure to the same people will help build bonds-based commitment, and limiting exposure to content not meeting individual topical interests will enhance identity-based commitment. Selectively presenting opportunities to reciprocate favors to others will induce normative commitment.

We identified one way that controlling access to information can be used to affect commitment. Anonymity may actually increase identity-based commitment. Of course, it is also likely to interfere with bonds-based commitment. We suspect that only in very special cases will anonymity have a net positive impact on member commitment to a community.

Finally, there are a variety of ways that designers can influence commitment without making changes to the structure or technological features of a community, just by changing the contextual information that provides a frame through which members understand what they are doing. To generate identity-based commitment, a name and tagline can help, as can articulating the community's goals or purpose, or highlighting an outgroup to compete with or an external threat. Highlighting interpersonal similarities among members can build bond-based commitment. Normative commitment can be enhanced through highlighting the importance of the community's purpose, testimonials about others' commitments, priming the norm of reciprocity and showing people how they have benefitted. Presenting another similar community as an outgroup to compete with is a double-edged sword. On the positive side, it may enhance identity-based commitment. On the negative side, it can reduce needs-based commitment, as members become more aware of an alternative community they could explore and possibly switch to.

As with many of the design alternatives presented in this book, the design claims do not imply definitive design guides. Some of the options discussed here, such as recruiting participants who have existing social ties, will, to the extent that they are feasible, enhance most online communities. But even those will generally have exceptions; for example, some people may be more comfortable sharing information about addictions or health problems with strangers than with friends. Many other design alternatives, such as homogeneity, small size, anonymity, offtopic communication, and competition with a related community, have different effects on 
different desirable outcomes. The right choices for building commitment in each particular community will depend on a careful analysis of that community, and healthy dose of designer intuition.

\begin{tabular}{|l|l|l|}
\hline Type & Design Alternative & Claim \# \\
\hline $\begin{array}{l}\text { Community } \\
\text { Structure }\end{array}$ & $\begin{array}{l}\text { Recruiting or clustering those who are similar to } \\
\text { each other into homogeneous groups }\end{array}$ & Design Claim 3 \\
\hline & $\begin{array}{l}\text { Creating named groups within a larger online } \\
\text { community }\end{array}$ & $\begin{array}{l}\text { Design claim 6, } \\
\text { Design claim 7 }\end{array}$ \\
\hline & $\begin{array}{l}\text { Recruiting participants who have existing social } \\
\text { ties }\end{array}$ & Design Claim 13 \\
\hline & $\begin{array}{l}\text { Large communities with a large volume of } \\
\text { communication }\end{array}$ & Design Claim 22 \\
\hline & $\begin{array}{l}\text { Diversity of members' interest in an online } \\
\text { community }\end{array}$ & Design Claim 23 \\
\hline & Making group members anonymous & Design Claim 12 \\
\hline $\begin{array}{l}\text { Content, Tasks, and } \\
\text { Activities }\end{array}$ & Participation under a pseudonym & Design Claim 19 \\
\hline & $\begin{array}{l}\text { Providing community members interdependent } \\
\text { tasks }\end{array}$ & Design Claim 9 \\
\hline & Facilitating interaction with “friends of friends” & Design Claim 14 \\
\hline & $\begin{array}{l}\text { Displaying photos and information about individual } \\
\text { members and their recent activities }\end{array}$ & Design Claim 15 \\
\hline & $\begin{array}{l}\text { Providing opportunities for members to engage in } \\
\text { personal conversation }\end{array}$ & Design Claim 16 \\
\hline & $\begin{array}{l}\text { Providing user profile pages and flexibility in } \\
\text { personalizing them }\end{array}$ & Design Claim 18 \\
\hline & Active self-disclosure with visible response & Design Claim 20 \\
\hline Off-topic communication & $\begin{array}{l}\text { Design Claim 24, } \\
\text { Design Claim 25 }\end{array}$ \\
\hline & $\begin{array}{l}\text { Cransfer them to other members } \\
\text { community-specific investments }\end{array}$ & Design Claim 34 \\
\hline & Design Claim 35 \\
\hline
\end{tabular}




\begin{tabular}{|c|c|c|}
\hline \multicolumn{3}{|l|}{ and filtering } \\
\hline & $\begin{array}{l}\text { Places, spaces, groups, friend feeds, and other } \\
\text { mechanisms that increase the likelihood that people } \\
\text { will encounter the same people they have } \\
\text { previously encountered }\end{array}$ & Design Claim 17 \\
\hline & $\begin{array}{l}\text { Personalized filters, which differentially expose } \\
\text { members to communications that match their } \\
\text { personal interests }\end{array}$ & Design Claim 26 \\
\hline & $\begin{array}{l}\text { Highlighting opportunities to return favors to } \\
\text { specific others }\end{array}$ & Design Claim 31 \\
\hline \multicolumn{3}{|l|}{$\begin{array}{l}\text { Presentation and } \\
\text { Framing }\end{array}$} \\
\hline & $\begin{array}{l}\text { Providing a collection of individuals with a name or } \\
\text { other indicator that they are members of a common } \\
\text { group }\end{array}$ & Design claim 4 \\
\hline & $\begin{array}{l}\text { A name and tagline that articulate the shared } \\
\text { interests of a community’s members }\end{array}$ & Design claim 5 \\
\hline & Making community fate, goals, or purpose explicit & Design Claim 8 \\
\hline & Highlighting an out-group (and competing with it) & Design Claim 10 \\
\hline & $\begin{array}{l}\text { Emphasizing a threat to the group, especially from } \\
\text { an external source, }\end{array}$ & Design Claim 11 \\
\hline & Highlighting interpersonal similarity & Design Claim 21 \\
\hline & $\begin{array}{l}\text { Highlighting a community's purpose and successes } \\
\text { at achieving that purpose }\end{array}$ & Design Claim 27 \\
\hline & $\begin{array}{l}\text { Testimonials about people's normative } \\
\text { commitment to the community }\end{array}$ & Design Claim 28 \\
\hline & $\begin{array}{l}\text { Priming norms of reciprocity by highlighting } \\
\text { concepts that get people to think of their normative } \\
\text { obligations }\end{array}$ & Design Claim 29 \\
\hline & $\begin{array}{l}\text { Showing people what they have received from the } \\
\text { community }\end{array}$ & Design Claim 30 \\
\hline & $\begin{array}{l}\text { Showing information about other communities in } \\
\text { the same ecological niche }\end{array}$ & Design Claim 33 \\
\hline
\end{tabular}


Abrams, D., Ando, K., \& Hinkle, S. (1998). Psychological attachment to the group: Crosscultural differences in organizational identification and subjective norms as predictors of workers' turnover intentions. Personality and Social Psychology Bulletin, 24(10), 10271039.

Allen, N., \& Meyer, J. (1996). Affective, Continuance, and Normative Commitment to the Organization: An Examination of Construct Validity. Journal of Vocational Behavior, 49(3), 252-276.

Amichai-Hamburger, Y. (2005). Internet minimal group paradigm. CyberPsychology \& Behavior, 8(2), 140-142.

Arkes, H., \& Blumer, C. (1985). The psychology of sunk cost. Organizational behavior and human decision processes, 35(1), 124-140.

Arkes, H., \& Hutzel, L. (2000). The role of probability of success estimates in the sunk cost effect. Journal of Behavioral Decision Making, 13(3), 295-306.

Aronson, E. (1997). Back to the Future: Retrospective Review of Leon Festinger's" A Theory of Cognitive Dissonance". The American Journal of Psychology, 110(1), 127-137.

Aronson, E., \& Mills, J. (1959). The effect of severity of initiation on liking for a group. Journal of Abnormal \& Social Psychology, 59, 177-181.

Back, M., Schmukle, S., \& Egloff, B. (2008). Becoming friends by chance. Psychological Science, 19(5), 439.

Baym, N. (1999). Tune In, Log on, Soaps, Fandom, and On-line Community. Newbury Park, CA: Corwin Pr.

Beenen, G., Ling, K., Wang, X., Chang, K., Dan Frankowski, Resnick, P., et al. (2004). Using social psychology to motivate contributions to online communities CSCW'04: Proceedings of the ACM Conference on Computer Supported Cooperative Work (pp. 212 - 221). New York: ACM Press.

Berscheid, E., \& Reis, H. T. (1998). Attraction and close relationships. In D. T. Gilbert, S. T. Fiske \& et al. (Eds.), The handbook of social psychology, Vol 2 (4th ed., pp. 193-281). New York, NY, US: McGraw-Hill.

Bossard, J. (1932). Residential propinquity as a factor in marriage selection. American Journal of Sociology, 38(2), 219-224. 
Bryant, S. L., Forte, A., \& Bruckman, A. (2005). Becoming Wikipedian: transformation of participation in a collaborative online encyclopedia Proceedings of the 2005 international ACM SIGGROUP conference on Supporting group work (pp. 1-10). New York: ACM Press.

Butler, B. (2001). Membership size, communication activity, and sustainability: A resourcebased model of online social structures. Information Systems Research, 12(4), 346-362.

Butler, B., Sproull, L., Kiesler, S., \& Kraut, R. (2007). Community effort in online groups: Who does the work and why? In S. Weisband. (Ed.), Leadership at a distance. (pp. 171-194). Hillsdale, NJ.: Lawrence Erlbaum Associates.

Byrne, D. (1997). An overview (and underview) of research and theory within the attraction paradigm. Journal of Social \& Personal Relationships, 14(3), 417-431.

Cameron, J., Banko, K. M., \& Pierce, W. D. (2001). Pervasive negative effects of rewards on intrinsic motivation: The myth continues. The Behavior Analyst, 24(1), 1-44.

Carron, A., \& Spink, K. (1995). The group size-cohesion relationship in minimal groups. Small Group Research, 26(1), 86.

Chen, P., \& Hitt, L. (2003). Measuring switching costs and the determinants of customer retention in Internet-enabled businesses: A study of the online brokerage industry. Information Systems Research, 13(3), 255-274.

Chen, Y., Harper, F., Konstan, J., \& Li, S. (In press). Social Comparisons and Contributions to Online Communities: A Field Experiment on MovieLens. American Economic Review.

Clary, E., Snyder, M., Ridge, R., Copeland, J., Stukas, A., Haugen, J., et al. (1998). Understanding and Assessing the Motivations of Volunteers: A Functional Approach. Journal of Personality and Social Psychology, 74, 1516-1530.

Collins, N., \& Miller, L. (1994). Self-disclosure and liking: A meta-analytic review. Psychological Bulletin, 116(3), 457-475.

Crain, A., Omoto, A., \& Snyder, M. (1998). What if you can't always get what you want? Testing a functional approach to volunteerism. Paper presented at the annual meetings of the Midwestern Psychological Association, Chicago, IL.

Curry, T., \& Emerson, R. (1970). Balance theory: A theory of interpersonal attraction? Sociometry, 33(2), 216-238. 
Dabbish, L., \& Kraut, R. E. (2008). Awareness Displays And Social Motivation For Coordinating Communication. Information Systems Research, 19(2), 221-238.

Deci, E. L., Koestner, R., \& Ryan, R. M. (1999). A meta-analytic review of experiments examining the effects of extrinsic rewards on intrinsic motivation. Psychological Bulletin, 125(6), 627-668.

Drenner, S., Sen, S., \& Terveen, L. (2008). Crafting the initial user experience to achieve community goals Proceedings of the 2008 ACM conference on Recommender systems (pp. 187-194): ACM New York, NY, USA.

Ducheneaut, N., \& Moore, R. J. (2004). The Social Side of Gaming: A Study of Interaction Patterns in a Massively Multiplayer Online Game CSCW'04: Proceedings of the ACM Conference on Computer-Supported Cooperative Work (pp. 360-369). NY: ACM Press.

Ducheneaut, N., Yee, N., Nickell, E., \& Moore, R. (2006). Alone together?: exploring the social dynamics of massively multiplayer online games.

Ducheneaut, N., Yee, N., Nickell, E., \& Moore, R. J. (2006). Building an MMO With Mass Appeal A Look at Gameplay in World of Warcraft. Games and Culture, 1(4), 1-38.

Dunbar, R. (1993). Co-evolution of neocortex size, group size and language in humans. Behavioral and brain sciences, 16(4), 681-735.

Eisenberger, R., Pierce, W. D., \& Cameron, J. (1999). Effects of reward on intrinsic motivation-negative, neutral and positive: comment on Deci, Koestner, and Ryan (1999). Psychol Bull, 125(6), 677-691.

Fehr, E., \& Gächter, S. (2000). Fairness and retaliation: The economics of reciprocity. The Journal of Economic Perspectives, 14(3), 159-181.

Festinger, L. (1957). A theory of cognitive dissonance: Stanford University Press.

Festinger, L., Riecken, H., Schachter, S., \& Aronson, E. (1956). When prophecy fails: University of Minnesota Press Minneapolis.

Festinger, L., Schacter, S., \& Back, K. (1950). Social pressures in informal groups: A study of human factors in housing. Palo Alto, CA: Stanford University Press.

Foltz, P., \& Dumais, S. (1992). Personalized information delivery: An analysis of information filtering methods. Communications of the ACM, 35(12), 51-60. 
Gaertner, S. L., Dovidio, J. F., Banker, B. S., Houlette, M., Johnson, K. M., \& McGlynn, E. A. (2000). Reducing intergroup conflict: From superordinate goals to decategorization, recategorization, and mutual differentiation. Group Dynamics, 4(1), 98-114.

Gerard, H. B., \& Mathewson, G. C. (1966). The effect of severity of initiation on liking for a group: A replication. Journal of Experimental Social Psychology, 2(3), 278-287.

Ghosh, R. (2005). Understanding free software developers: Findings from the FLOSS study Perspectives on free and open source software (pp. 23-45). Cambridge, MA USA: MIT Press.

Gouldner, A. W. (1960). The norm of reciprocity: A preliminary statement. American Sociological Review, 25(2), 161-178.

Granovetter, M. (1973). The strength of weak ties. American Journal of Sociology, 78primary, 1360-1380.

Gross, N., \& Martin, W. (1952). On group cohesiveness. American Journal of Sociology, 57(6), 546-564.

Hancock, J., Toma, C., \& Fenner, K. (2008). I know something you don't: the use of asymmetric personal information for interpersonal advantage.

Harper, F., Moy, D., \& Konstan, J. (2009). Facts or friends?: distinguishing informational and conversational questions in social Q\&A sites CHI'09: ACM conference on human factors in computing systems (pp. 759-768). New York: ACM.

Harper, F., Sen, S., \& Frankowski, D. (2007). Supporting social recommendations with activitybalanced clustering Proceedings of the ACM Conference On Recommender Systems (pp. 165-168). New York: ACM.

Heider, F. (1958). The psychology of interpersonal relations: Wiley New York.

Hinds, P., Carley, K., Krackhardt, D., \& Wholey, D. (2000). Choosing Work Group Members: Balancing Similarity, Competence, and Familiarity. Organizational Behavior and Human Decision Processes, 81(2), 226-251.

Hirschman, A. (1970). Exit, voice, and loyalty: Responses to decline in firms, organizations, and states: Harvard Univ Pr.

Hogg, M. (1992). The social psychology of group cohesiveness: From attraction to social identity: Harvester Wheatsheaf. 
Hogg, M., \& Abrams, D. (1988). Social identifications: A social psychology of intergroup relations and group processes: Routledge.

Hogg, M., \& Turner, J. (1985). When liking begets solidarity: An experiment on the role of interpersonal attraction in psychological group formation. British Journal of Social Psychology, 24(4), 267-281.

Hogg, M. A., \& Terry, D. J. (2000). Social Identity and Self-Categorization Processes in Organizational Contexts. The Academy of Management Review, 25(1), 121-140.

Homans, G. C. (1958). Social behavior as exchange. The American Journal of Sociology, 63(6), 597-606.

Homans, G. C. (1961). Social behavior: Its elementary forms. New York: Harcourt, Brace \& World.

Honeycutt, C. (2005). Hazing as a Process of Boundary Maintenance in an Online Community Journal of Computer-Mediated Communication, 10(2), np.

Hulin, C., Roznowski, M., \& Hachiya, D. (1985). Alternative opportunities and withdrawal decisions: Empirical and theoretical discrepancies and an integration. Psychological bulletin, 97(2), 233-250.

Hutchison, P., Jetten, J., Christian, J., \& Haycraft, E. (2006). Protecting threatened identity: Sticking with the group by emphasizing ingroup heterogeneity. Personality and Social Psychology Bulletin, 32(12), 1620.

Jeffries, R., Kiesler, S., Goetz, J., \& Sproull, L. (2000). Systers: Contradictions in community. Retrieved June 14, 2010:

http://citeseerx.ist.psu.edu/viewdoc/download?doi=10.1.1.111.9648\&rep=rep1\&type=pdf

Joeblo Movie Club (2005). Basic rules and guidelnes Retrieved Dec 6, 2005, from http://www.joblo.com/forums/announcement.php?s=641f9cd5b47beab4ad423f0c861dba 3c\&forumid=21

Jones, Q., Ravid, G., \& Rafaeli, S. (2002). An Empirical Exploration of Mass Interaction System Dynamics: Individual Information Overload and Usenet Discourse. Paper presented at the 35th Hawaii International Conference on System Sciences, Waikoloa, Big Island, Hawaii.

Kim, A. J. (2000). Community building on the web: Secret Strategies for Successful Online Communities. Berkeley, CA: Peachpit Press. 
Kittur, A., \& Kraut, R. E. (2008). Harnessing the Wisdom of Crowds in Wikipedia:: Quality Through Coordination CSCW'08: Proceedings of the ACM Conference on ComputerSupported Cooperative Work (pp. 37-46). New York: ACM Press.

Krackhardt, D., \& Porter, L. W. (1986). The Snowball Effect: Turnover Embedded in Communication Networks55. Journal of Applied Psychology, , 71: 50-, 50-55.

Landauer, T. K., Foltz, P. W., \& Laham, D. (1998). Introduction to Latent Semantic Analysis. Discourse Processes,, 25., 259-284.

Leskovec, J., Huttenlocher, D., \& Kleinberg, J. (2010). Signed networks in social media CHI 2010: Proceedings of the ACM conference on human factors in computing systems (pp. 1361-1370). New York: ACM.

Lewin, K. (1951). Field theory in social science; selected theoretical papers (D. Cartwright ed.). New York.: Harper \& Row.

Lott, A., \& Lott, B. (1965). Group cohesiveness as interpersonal attraction: A review of relationships with antecedent and consequent variables. Psychological bulletin, 64(4), 259-309.

McKenna, K., Green, A. S., \& Gleason, M. (2002). Relationship formation on the Internet: What's the big attraction? Journal of Social Issues, 58(1), 9-31.

Meyer, J., \& Allen, N. (1991). A three-component conceptualization of organizational commitment. Human resource management review, 1(1), 61-89.

Meyer, J., Stanley, D., Herscovitch, L., \& Topolnytsky, L. (2002). Affective, continuance, and normative commitment to the organization: A meta-analysis of antecedents, correlates, and consequences. Journal of vocational behavior, 61(1), 20-52.

Michinov, N., Michinov, E., \& Toczek-Capelle, M. (2004). Social Identity, Group Processes, and Performance in Synchronous Computer-Mediated Communication. Group Dynamics: Theory, Research, and Practice, 8(1), 27-39.

Milgram, S. (1977). The Familiar Stranger: An Aspect of Urban Anonymity. In S. Milgram (Ed.), The individual in a social world : essays and

experiments. Reading, Mass: .: Addison-Wesley Pub. Co., 1977.

Newcomb, T. (1961). The acquaintance process. New York: Holt, Rinehart, \& Winston. 
Nov, O. (2007). What motivates wikipedians? Communications of the ACM, 50(11), 60-64.

Nowak, M., \& Sigmund, K. (2005). Evolution of indirect reciprocity. Nature, 437(7063), 12911298.

Pichon, I., Boccato, G., \& Saroglou, V. (2007). Nonconscious influences of religion on prosociality: A priming study. European Journal of Social Psychology, 37(5), 1032.

Postmes, T., Spears, R., \& Lea, M. (2002). Intergroup differentiation in computer-mediated communication: Effects of depersonalization. Group Dynamics, 6(1), 3-16.

Postmes, T., Spears, R., \& Lea, M. (2002). Intergroup differentiation in computer-mediated communication: Effects of depersonalization. Group Dynamics, 6(1), 3-16.

Postmes, T., Spears, R., Lee, A. T., \& Novak, R. J. (2005). Individuality and Social Influence in Groups: Inductive and Deductive Routes to Group Identity. Journal of Personality and Social Psychology, 89(5), 747-763.

Postmes, T., Spears, R., Sakhel, K., \& de Groot, D. (2001). Social influence in computermediated communication: The effects of anonymity on group behavior. Personality \& Social Psychology Bulletin, 27(10), 1243-1254.

Raymond, E. S. (2003, December 29). The Jargon File Available from http://www.catb.org/jargon/

Ren, Y., Harper, F. M., Drenner, S., Terveen, L., Kiesler, S., Riedl, J., et al. (Under review). Increasing Attachment to Online Communities: Designing from Theory. MIS Quarterly.

Ren, Y., \& Kraut, R. E. (Under review). A Simulation for Designing Online Community: Member Motivation, Contribution, and Discussion Moderation. Information Systems Research.

Ren, Y., Kraut, R. E., \& Kiesler, S. (2007). Applying Common Identity and Bond Theory to the Design of Online Communities Organizational Studies, 28(3), 379-410.

Resnick, P., Hansen, D., Riedl, J., Terveen, L., \& Ackerman, M. (2005). Beyond threaded conversation. Conference on Human Factors in Computing Systems, 2138-2139.

Resnick, P., Janney, A., Buis, L. R., \& Caroline R Richardson (in press). Starting an Online Community on Demand: A Case Study of Adding Forums to a Physical Activity Promotion Program Journal of Medical Internet Research. 
Resnick, P., Zeckhauser, R., Swanson, J., \& Lockwood, K. (2006). The value of reputation on eBay: A controlled experiment. Experimental Economics, 9(2), 79-101.

Ridings, C. M., \& Gefen, D. (2004). Virtual community attraction: Why people hang out online. Journal of Computer Mediated Communication, 10(1), np.

Rogers, P., \& Lea, M. (2005). Social presence in distributed group environments: The role of social identity. Behaviour \& Information Technology, 24(2), 151-158.

Sassenberg, K. (2002). Common bond and common identity groups on the Internet: Attachment and normative behavior in on-topic and off-topic chats. Group Dynamics: Theory and Practice, 6(1), 27-37.

Sassenberg, K., Boos, M., Postmes, T., \& Reips, U.-D. (2003). Studying the Internet: A challenge for modern psychology. Swiss Journal of Psychology - Schweizerische Zeitschrift fèur Psychologie - Revue Suisse de Psychologie, 62(2), 75-77.

Sassenberg, K., \& Postmes, T. (2002). Cognitive and strategic processes in small groups: Effects of anonymity of the self and anonymity of the group on social influence. British Journal of Social Psychology, 41(3), 463-480.

Shapiro, C., \& Varian, H. (1999). Information rules: A strategic guide to the network economy. Boston, MA: Harvard Business School Press.

Sherif, M., Harvey, L. J., White, B. J., Hood, W. R., \& Sherif, C. W. (1961). Intergroup conflict and cooperation: The Robbers Cave experiment: . Middletown, CT: Wesleyan University Press (Reprinted in 1988).

Slater, M., Sadagic, A., Usoh, M., \& Schroeder, R. (2000). Small-group behavior in a virtual and real environment: A comparative study. Presence: Teleoperators \& Virtual Environments, 9(1), 37-51.

Smith, C. B., McLaughlin, M. L., \& Osborne, K. K. (1997). Conduct Control on Usenet Journal of Computer Mediated Communication, 2(4), np.

Spertus, E., Jeffries, R., \& Sie, K. (2001). Scaling Online Communities with Javamlm. Paper presented at the Fifteenth Systems Administration Conference (LISA), USENIX San Diego, CA. .

Stewart, K. J., \& Gosain, S. (2006). The Impact of Ideology on Effectiveness in Open Source Software Development Teams. MIS Quarterly, 30(2), 291-314. 
Sykes, R., Larntz, K., \& Fox, J. (1976). Proximity and similarity effects on frequency of interaction in a class of naval recruits. Sociometry, 39, 263-269.

Tajfel, H., Billig, M. G., Bundy, R. P., \& Flament, C. (1971). Social categorization and intergroup behaviour. European Journal of Social Psychology, Vol. 1(20046-2772), 149178.

Tedjamulia, S., Dean, D., Olsen, D., \& Albrecht, C. (2005). Motivating content contributions to online communities: Toward a more comprehensive theory Proceedings of the 38th Annual Hawaii International Conference on System Sciences (CD) (pp. 193b). Waikoloa, Big Island, Hawaii Computer Society Press.

Thibaut, J., \& Kelley, H. (1986). The social psychology of groups: Transaction Publishers.

Turner, J. (1985). Social categorization and the self-concept: a social cognitive theory of group. Advances in group processes, 2, 77-121.

Utz, S. (2003). Social identification and interpersonal attraction in MUDs. Swiss Journal of Psychology, 62(2), 91-101.

Walther, J. B., Slovacek, C. L., \& Tidwell, L. C. (2001). Is a picture worth a thousand words?: Photographic images in long-term and short-term computer-mediated communication. Communication Research, 28(1), 105-134.

Wang, X. (2007). An ecological perspective on online communities. Unpublished Ph.D. thesis, Univesity of Pittsburgh, Pittsburgh PA.

Wasko, M. M., \& Faraj, S. (2005). Why Should I Share? Examining Social Capital and Knowledge Contribution in Electronic Networks of Practice. MIS Quarterly, 29(1), 3557.

Williams, K., \& O'Reilly, C. (1998). Demography and diversity in organizations: A review of 40 years of research. Research in Organizational Behavior, 20, 77-140.

Williamson, I., Snyder, M., \& Omoto, A. M. (2000, May). How motivations and re-enlistment frames interact to predict volunteer attitudes and intentions: A test of the functional matching effect. Paper presented at the annual meetings of the Midwestern Psychological Association, Chicago, IL.

Worchel, S., Rothgerber, H., Day, E., Hart, D., \& Butemeyer, J. (1998). Social identity and individual productivity within groups. British Journal of Social Psychology, 37, 389-414. 
Yamagishi, T., \& Kiyonari, T. (2000). The group as the container of generalized reciprocity. Social Psychology Quarterly, 63(2), 116-132.

Yee, N., Bailenson, J., \& Rickertsen, K. (2007). A meta-analysis of the impact of the inclusion and realism of human-like faces on user experiences in interfaces.

Yuki, M., Maddux, W., Brewer, M., \& Takemura, K. (2005). Cross-cultural differences in relationship-and group-based trust. Personality and Social Psychology Bulletin, 31(1), 48.

Zaccaro, S., \& Dobbins, G. (1989). Contrasting group and organizational commitment: Evidence for differences among multilevel attachments. Journal of Organizational Behavior, 10(3), 267-273. 